Article

\title{
Integration of a Combined Cycle Power Plant with MED-RO Desalination Based on Conventional and Advanced Exergy, Exergoeconomic, and Exergoenvironmental Analyses
}

\author{
Mohammad Hasan Khoshgoftar Manesh ${ }^{1,2}, *$, Reza Shojaei Ghadikolaei ${ }^{1,2} \mathbb{D}$, Hossein Vazini Modabber ${ }^{2}(\mathbb{D}$ and \\ Viviani Caroline Onishi ${ }^{3, * \text { (ID }}$ \\ 1 Energy, Environment and Biologic Research Lab (EEBRlab), Division of Thermal Sciences and \\ Energy Systems, Department of Mechanical Engineering, Faculty of Technology \& Engineering, \\ University of Qom, Qom 3716146611, Iran; rezashojaei1313@yahoo.com \\ 2 Center of Environmental Research, Qom 3716146611, Iran; hossein.vazini2@gmail.com \\ 3 School of Engineering and the Built Environment, Edinburgh Napier University, Merchiston Campus, \\ 10 Colinton Road, Edinburgh EH10 5DT, UK \\ * Correspondence: m.khoshgoftar@qom.ac.ir (M.H.K.M.); V.Onishi@napier.ac.uk (V.C.O.)
}

\section{check for}

updates

Citation: Khoshgoftar Manesh, M.H.; Ghadikolaei, R.S.; Modabber, H.V.;

Onishi, V.C. Integration of a

Combined Cycle Power Plant with

MED-RO Desalination Based on

Conventional and Advanced Exergy,

Exergoeconomic, and

Exergoenvironmental Analyses.

Processes 2021, 9, 59. https://doi.org/

$10.3390 /$ pr9010059

Received: 7 November 2020

Accepted: 25 December 2020

Published: 29 December 2020

Publisher's Note: MDPI stays neutral with regard to jurisdictional clai$\mathrm{ms}$ in published maps and institutional affiliations.

Copyright: (C) 2020 by the authors. Licensee MDPI, Basel, Switzerland. This article is an open access article distributed under the terms and conditions of the Creative Commons Attribution (CC BY) license (https:// creativecommons.org/licenses/by/ $4.0 /)$.

\begin{abstract}
The ever-increasing world population, change in lifestyle, and limited natural water and energy resources have made industrial seawater desalination plants the leading contenders for cost-efficient freshwater production. In this study, the integration of a combined cycle power plant (CCPP) with multi-effect distillation (MED) and reverse osmosis (RO) desalination units is investigated through comprehensive conventional and advanced exergy, exergoeconomic, and exergoenvironmental analyses. Firstly, the thermodynamic modelling of the CCPP is performed by using a mathematical programming procedure. Then, a mathematical model is developed for the integration of the existing CCPP plant with MED and RO desalination units. Finally, conventional and advanced exergy, exergoeconomic, and exergoenvironmental analyses are carried out to assess the main performance parameters of the integrated CCPP and MED-RO desalination system, as well as to identify potential technical, economic, and environmental improvements. A case study is presented based on the Shahid Salimi Neka power plant located at the north of Iran along the Caspian Sea. The mathematical modelling approach for the integrated CCPP and MED-RO desalination system is solved in MATLAB, and the results are validated via Thermoflex software. The results reveal an increase of $3.79 \%$ in fuel consumption after the integration of the CCPP with the desalination units. The exergy efficiency of the integrated system is $42.7 \%$, and the highest cost of exergy destruction of the combustion chamber is 1.09 US\$ per second. Economic and environmental analyses of the integrated system also show that gas turbines present the highest investment cost of 0.047 US\$ per second. At the same time, MED exhibits the highest environmental impact rate of 0.025 points per second.
\end{abstract}

Keywords: mathematical modelling and simulation; desalination; water and power production; combined cycle power plant (CCPP); multi-effect distillation (MED); reverse osmosis (RO); advanced exergy analysis; exergoeconomic analysis; exergoenvironmental analysis

\section{Introduction}

The pressing need of human societies for energy allied to the limited energy resources and its increasing prices have led many experts and scientists to find a way to optimize energy consumption. In this light, the design of a power plant with maximum efficiency in terms of energy consumption has become a significant challenge today. Besides, the reliable provision of freshwater is also an emerging issue, particularly in water-stressed countries. Thus, the implementation of new multi-purpose power plants, as well as the retrofit of existing single-purpose ones to produce power and water have received increased interest 
from the literature in the past few years. One way of converting existing single-purpose power plants into multi-purpose ones is by recovering and reusing the waste heat from the system. The waste heat can be utilized for local heating and cooling, and in the form of steam for the production of freshwater in industrial desalination plants.

The design of integrated power plants with desalination systems is a very complex task, which usually involves the optimization of several thermodynamic, economic, and environmental aspects at once. In this context, Najafi et al. [1] have proposed a comprehensive study on the thermodynamic, economic, and environmental costs of a combined gas turbine and fuel cell system coupled to a desalination unit. The authors have considered two different objective functions to optimize the integrated system. Thus, the exergy efficiency and overall cost rate are optimized via a genetic algorithm-based approach, aiming at reducing the overall cost while increasing the exergy efficiency of the system. They have also examined the rate of return of investment and concluded that the cost of the investment can be fully repaid after 9 years. Vazini et al. [2] have studied the optimal coupling of a site utility steam network to a desalination system by applying total site analysis and exergoeconomic optimization. The authors have showed that the steam network used by various processes on a site, in addition to providing the required steam for each component, can also meet the required steam of the desalination unit. They have also examined the potential coupling a power plant unit to a multi-effect distillation (MED) and reverse osmosis $(\mathrm{RO})$ desalination system by assessing the process fuel consumption, and power and heat outputs.

Al-Zahrani et al. [3] have conducted a theoretical study on a hybrid system consisting of a gas turbine unit, and a membrane and thermal desalination units. The authors have proposed a modelling approach for a MED-RO system coupled to a gas turbine cycle, by taken into account energy and exergy efficiencies for different equipment in the integrated system. This study has also investigated the effects of the main parameters of the gas turbine, such as inlet temperature and pressure rate on the production of freshwater. They have also evaluated the degree of exergy destruction for various components of the system. Sadri et al. [4] have proposed a thermodynamic model to predict the performance of a multi-effect steam desalination system. The authors have performed a comprehensive exergy efficiency analysis of a RO desalination unit. They have also developed a model to optimize the system irreversibility and exergy destruction, by using genetic algorithms.

Blanco-Marigorta et al. [5] have presented the exergy-environmental analysis of a membrane desalination unit located in the Canary Islands. The authors have performed an exergy analysis and a life cycle analysis to evaluate the main environmental parameters of the system. They have concluded that the highest exergy destruction occurs in the $\mathrm{RO}$ and high-pressure pump units. They have stated that the environmental impacts can be decreased by reducing the amount of exergy destruction of these components. Calise et al. [6] have examined a renewable-driven multi-generation system composed of a solar field, absorption chiller, biomass heaters, and a MED desalination unit. They have performed exergy and exergoeconomic analysis to identify process units with greatest impact on exergy efficiency.

Mokhtari et al. [7] have investigated the simultaneous integration of a gas turbine with MED and RO desalination plants in Bashagard city. The authors have concluded that the integrated system can met the electricity and freshwater demands in the region. Almutairi et al. [8] have proposed a comprehensive approach for cogeneration systems based on energy and exergy analyses of real data. They have used IPSEPRO software to combine the MED desalination and a thermal compressor. The authors have appraised the performance of the system under different thermodynamic and environmental conditions. They have found that the highest system irreversibility is related to the thermo-compressor and desalination effects. They have also concluded that the system efficiency can be increased by changing some process conditions, which include lowering the ambient temperature, increasing the pressure rate, as well as by rising the feedwater temperature. 
Shahzad et al. [9] have developed a new method for categorizing fuel costs in an integrated system of a combined cycle power plant (CСPP) and desalination unit. The authors have considered exergy destruction as an important factor in categorizing fuel costs. Their results reveal that power turbines mainly use changes in the enthalpy energy of steam at high pressures and temperatures, while desalination plants (especially multieffect plants) depend only on the latent heat of steam. In addition, the exergy destruction imposed by desalination units is about 2 to $7 \%$ of the total exergy destruction. Eveloy et al. [10] have investigated a system consisting of a solid oxide fuel cell, gas turbine, and $\mathrm{RO}$ desalination plant. They have examined the integrated system from a thermodynamic and economic point of view, and considered different fluids in the Rankine organic cycle. Their results show that the power output of the hybrid cycle varies from 1.2 to $2.4 \mathrm{MW}$, depending on the selected organic fluid. Their results also indicate that US\$ 8 million to US\$ 21 million can be saved per year in terms of water and gas expenses.

$\mathrm{Ng}$ et al. [11] have proposed an optimization approach to improve the exergy efficiency of a large-scale water desalination unit. Based on an economic analysis, Arani et al. [12] have concluded that the ease of access is one of the most important factors in increasing the cost of a unit over the years. They have proposed a new model for economic analysis by assessing the relationship between the cost of a unit and its ease of access. In their analysis, the authors have investigated the integration of a combined cycle of gas turbines and a desalination unit. Moreover, different economic parameters including the net present value and repayment period have been examined in the two units with fixed and timevarying access. They have determined that unit's access availability is a critical factor in systems with severe destruction and prolonged overhauls. Salimi and Amidpour [13] have investigated the integration of different desalination systems into cogeneration units. In their study, the authors have used the R-CURVE diagram to analyze the integration of MED and RO desalination units with co-production systems to reduce the overall system cost. They have found that the R-CURVE diagram can be a useful and powerful diagram for examining the effects of this integration on system performance.

Ameri et al. [14] have investigated the exergy analysis of a 420 MW NEKA combined cycle power plant. The authors have evaluated the thermal and exergy efficiency of the plant. Vazini and Khoshgoftar Manesh [15] have focused on the optimization of a water desalination unit integrated with the Qeshm power and water production plant. The authors have developed a multi-objective model based on genetic algorithms. The objective functions are selected to maximize the exergy efficiency, while the economic and environmental performance parameters are minimized in their multi-objective optimization approach. Thermodynamic modelling and simulation have been performed in MATLAB software (R2014a, MathWorks, atick, Massachusetts, USA, 2014), and its validation performed with the results from Thermoflex software and real results of the Qeshm site. Their results show $\sim 24 \%$ of increase in exergy efficiency and a significant decrease in the costs and the environmental impacts of the system. Moghimi et al. [16] have investigated an integrated system for the production of cooling, heating, power, and freshwater for domestic use. In this study, the authors have evaluated the system in terms of exergy and energy of different operating conditions. The results show that the proposed system is capable of supplying freshwater at $\sim 86 \mathrm{~kg} / \mathrm{s}$, as well as generating $30 \mathrm{MW}$ of electricity, $2 \mathrm{MW}$ for the cooling system, and 1.1 MW for the heating system. Finally, the exergy destruction is $\sim 56 \mathrm{MW}$, whereas the exergy and energy efficiencies are equal to $36 \%$ and $39 \%$, respectively.

In this study, the integration of a CCPP with MED and RO desalination units is investigated through comprehensive conventional and advanced exergy, exergoeconomic, and exergoenvironmental analyses. The thermodynamic modelling of the integrated CCPP and MED-RO desalination system is performed in MATLAB software by using a programming procedure, and the results obtained are validated via Thermoflex software. In addition, conventional and advanced exergy, exergoeconomic, and exergoenvironmental analyses are carried out to assess the main process performance parameters, as well as to identify potential technical, economic, and environmental improvements for the integrated CCPP 
and MED-RO system. Hence, the exergy destruction rate of the equipment is calculated using conventional exergy analysis. This analysis allows identifying the components that present more potential for improvements according to their rate of exergy destruction. On the other hand, performing an advanced exergy analysis provides a more detailed perspective. In advanced analysis, the exergy destruction rate of equipment is divided into two parts: (i) avoidable/unavoidable exergy destruction; and, (ii) endogenous/exogenous exergy destruction [17]. In the advanced exergy analysis, the potential for improvements of process components is evaluated by the share of avoidable and endogenous exergy destruction. Therefore, the advanced exergy analysis has the ability to more accurately identify the improvement potential of different units of the system. A case study is performed based on the Shahid Salimi Neka power plant located at the north of Iran along the Caspian Sea. To the best of our knowledge, this is the first study applying advanced exergy analysis to investigate the integration of MED-RO desalination system to the Neka CCPP. Thus, innovative features of this work include assessing the effects of the desalination and power plant system integration, as well as identifying potential system improvements by performing both conventional and advanced exergy, exergoeconomic, and exergoenvironmental analyses.

\section{Process Description}

A combined cycle power plant (CCPP) consists of a combination of steam turbine and gas turbine cycles. In the CCPP process, gas turbine generators produce electricity, while the waste heat energy from combustion products of the gas turbine (GT) is used to generate the steam required to drive the steam turbine (ST). Note that additional electricity is needed in the latter process. The CCPP layout can vary depending on the type of turbines, heat recovery boilers, and recovery devices used in the system. The efficiency of the power plant can be considerably increased by combining the steam and gas turbine cycles. The electrical efficiency of a simple power plant without waste heat recovery is typically between $25-40 \%$, while the CСPP has an efficiency of about $60 \%$.

The Shahid Salimi Neka power plant (hereafter, referred to as Neka power plant) is a CCPP located in the vicinity of the city of Neka and the Caspian Sea at the north of Iran. The Neka power plant is composed of two GTs, one ST, two air compressors (ACs), two heat recovery steam generators (HRSGs), one combustion chamber (CC), and a plate condenser with a cooling system based on seawater. The GTs used in this cycle are of a V94.2 type with a production capacity of $132.15 \mathrm{MW}$. Since the GTs were installed in 1982, their operating parameters will differ from a new gas turbine. The temperature of the exhaust gases from the GTs enters the double pressure boiler at ambient temperature and produces steam at $520^{\circ} \mathrm{C}$ and $230^{\circ} \mathrm{C}$ in the high and low-pressure sections, respectively. The production capacity of the ST in this plant is about $160.8 \mathrm{MW}$, and the total CCPP capacity is $420 \mathrm{MW}$ [14]. The schematic diagram of the Neka power plant is shown in Figure 1.

This study examines the thermodynamic feasibility of coupling a multi-effect distillation (MED) and reverse osmosis (RO) desalination system to the existing Neka power plant. The schematic diagram of the proposed power and freshwater production plant is depicted in Figure 2. According to this schematic diagram, airflow first enters the AC with a temperature of $20{ }^{\circ} \mathrm{C}$. The compression process increases the airflow pressure to about 10.8 times. Then, the compressed air is combined with the fuel in the CC and its outlet temperature rises to about $970{ }^{\circ} \mathrm{C}$. In the next stage, the hot and compressed outlet flow with significant energy enters the GT section. The GT spends part of this energy on moving the compressor, and the rest as the net power of the turbine itself. The combustion products from GTs have a good potential in terms of heat. 


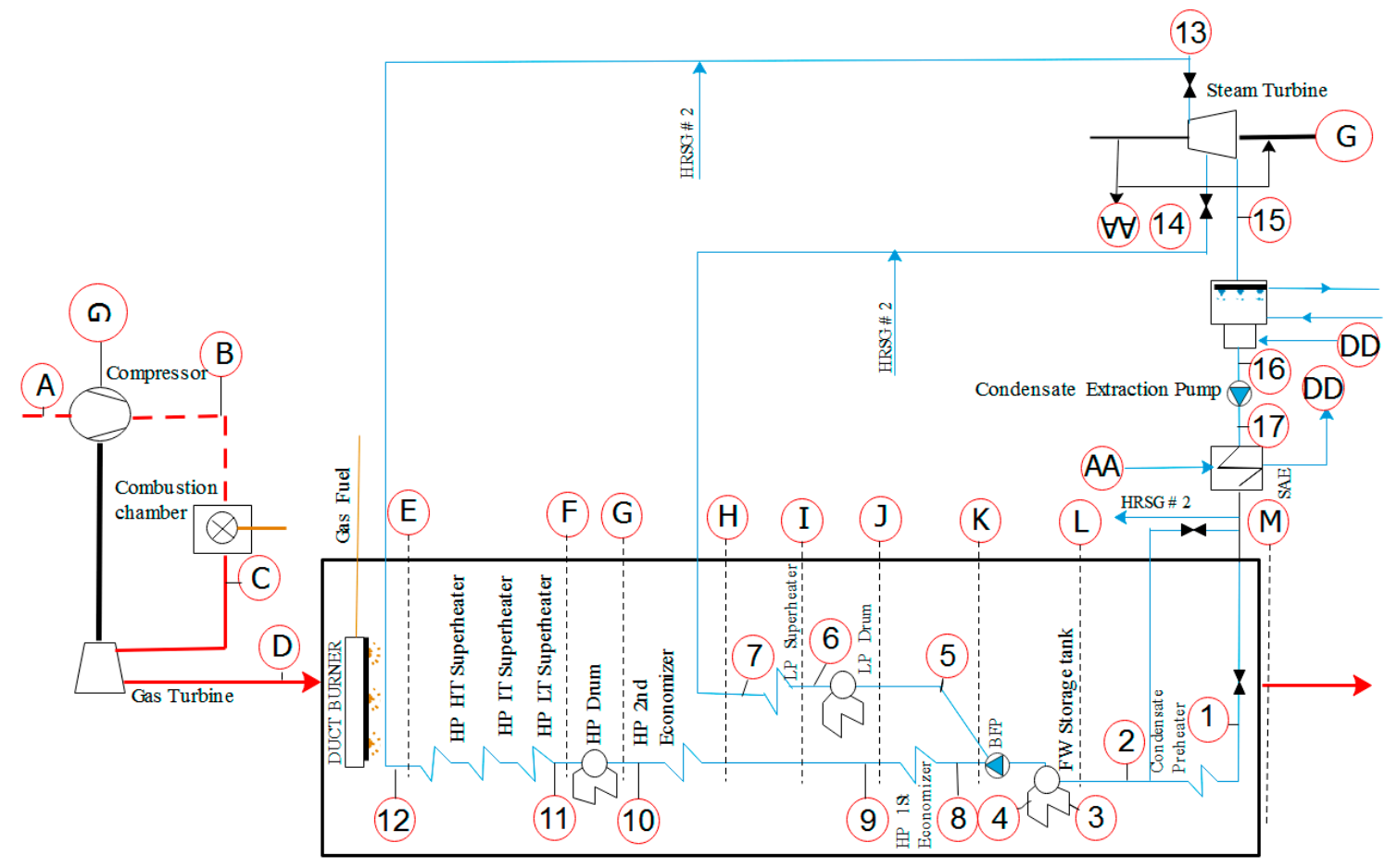

Figure 1. Schematic diagram of Shahid Salimi Neka power plant. HRSG, heat recovery steam generator as proposed by Ameri et al. [14]. Reprinted figure with permission from Ameri, M., Ahmadi, P., Khanmohammadi, S. Exergy analysis of a $420 \mathrm{MW}$ combined cycle power plant. 2008, 32, 175-183.

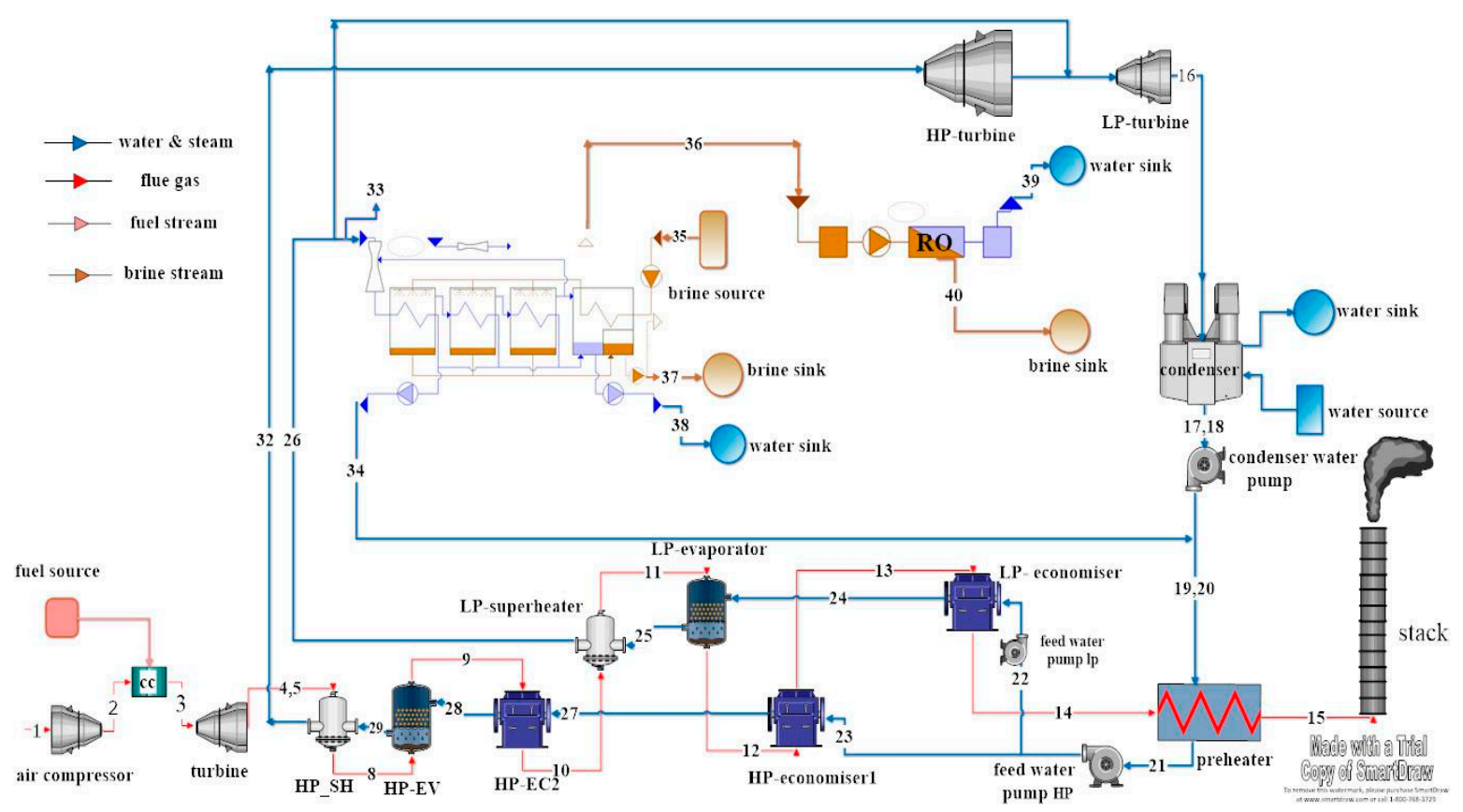

Figure 2. Schematic diagram of the new integrated combined cycle power plant (CCPP) with multi-effect distillation (MED) and reverse osmosis (RO) desalination system. LP, low-pressure; HP, high-pressure.

In combined power cycles, the loss of heat can be prevented by bypassing the combustion products through various process components to produce high-pressure steam, and use it to generate power in the ST. Note that the combustion products from GTs enter the high-pressure (HP) superheater. This is the first equipment in the HRSG unit. By bypassing combustion products through the HP superheater, the steam temperature should reach 
$533{ }^{\circ} \mathrm{C}$ to provide the necessary conditions for use in the steam turbine. In the next step, the combustion products enter the low-pressure (LP) evaporator.

The LP evaporator uses the combustion products heat to convert the water phase from a liquid to vapor state, and prepare it for entering the HP superheater. The economizer is a transducer that uses waste heat to raise the temperature of the inlet water to the saturation temperature at the same pressure, after which the evaporator can generate the demanded steam. Next, the combustion products enter the feedwater preheater before finally reaching the chimney and open-air section. In the LP section of the HRSG, and after the LP superheater, the LP steam flow is divided into two streams. One stream enters the LP section of the ST, where it is mixed with the outlet stream from the HP-ST. The second LP steam stream enters the MED plant, where it provides the required steam for driving the first desalination effect. The schematic diagram of the proposed MED desalination unit is displayed in Figure 3.

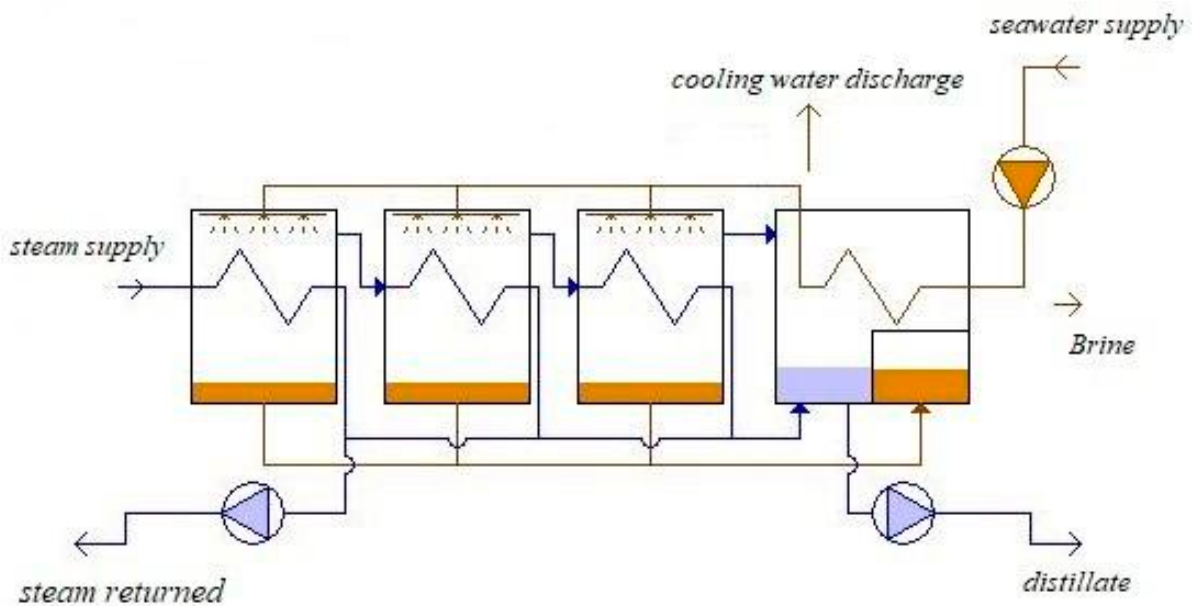

Figure 3. Schematic of the multi-effect distillation (MED) system.

In the MED section, seawater first enters the desalination condenser at seawater temperature $\left(20^{\circ} \mathrm{C}\right)$. The inlet seawater is used as the cooling water of the desalination condenser and converts the steam supply into a liquid state. After a little warming, the seawater is directed to two different system components. One part enters the MED desalination effects as feedwater, while the other one leaves the condenser unit as cooling water discharge and return to the sea (if there is no RO unit downstream). Note that the MED unit is driven by the steam from the LP section of the HRSG unit of the CCPP. The feedwater is sprayed from above onto the pipes containing hot steam and part of it evaporates in the process, due to the low pressure of the effects and high temperature.

The rest of the feedwater moves as a brine with progressively higher salinity towards the exit of the desalination unit. The steam produced by the evaporation of saltwater enters the unit as a stimulus side effect. After the first MED effect, the supply steam turns into a liquid state due to heat loss, and leaves the desalination unit. This flow, referred to as "steam returned", is then mixed with the outlet flow from the CCPP condenser to be used as feedwater of the HRSG unit. The produced distillate is extracted from the desalination condenser as a freshwater stream. In a MED plant, the cooling water discharge from the condenser has a higher temperature than seawater. However, its salinity is equal to that of seawater. To increase the amount of freshwater produced, the cooling water discharge stream can be used as feedwater for a RO desalination unit. Figure 4 shows a schematic diagram for the $\mathrm{RO}$ desalination unit considered in this study. 


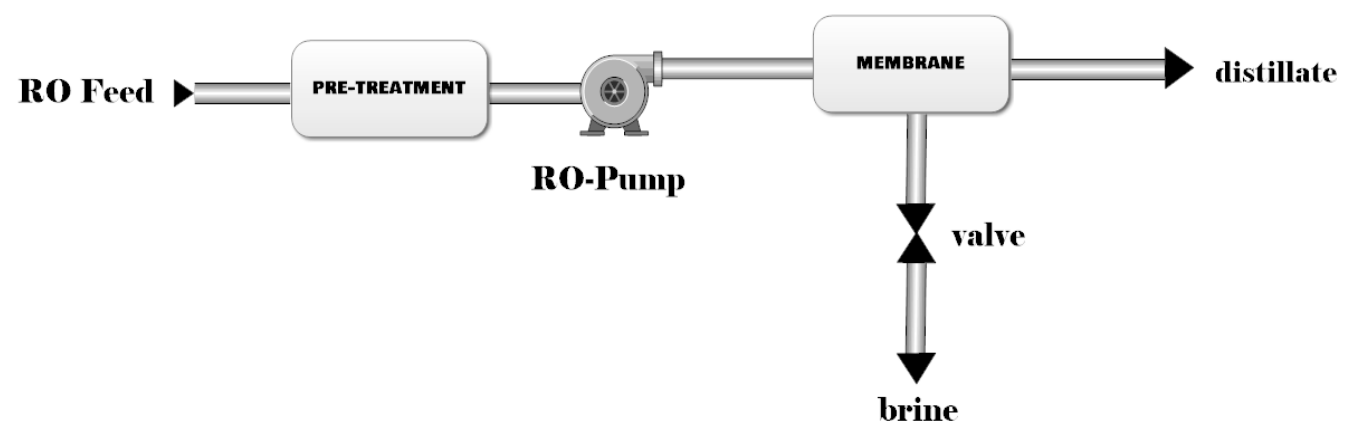

Figure 4. Schematic diagram of the reverse osmosis (RO) desalination unit.

According to Figure 4, the cooling water discharge from the MED system, that is, the $\mathrm{RO}$ feedwater enters a pre-treatment unit for removal of its large and suspended particles. This stream is then pumped into the RO membrane due to mechanical pressure. The membrane removes the salt from the feedwater and produces freshwater. It is noted that overcoming the osmotic pressure difference between freshwater and saltwater is the basis of the $\mathrm{RO}$ desalination process.

\section{Methodology}

3.1. Thermodynamic Modelling of the Integrated CCPP and MED-RO System

For better modelling the gas and steam turbine cycles of the CCPP, a set of default values is considered as input data. This data is obtained from the operational information of the Neka power plant, as well as the weather conditions around the location of the plant. The input data related to gas and steam cycles are gathered in Tables 1 and 2, respectively.

Table 1. Technical input data of the gas turbine cycle [18].

\begin{tabular}{ccc}
\hline Input Parameter & Symbol & Value (Unit) \\
\hline Ambient temperature & $T_{0}$ & $20\left({ }^{\circ} \mathrm{C}\right)$ \\
Turbine inlet temperature & $T_{I N_{-} T U R B}$ & $971\left({ }^{\circ} \mathrm{C}\right)$ \\
AC compression ratio & $r_{p, A C}$ & 10 \\
AC isentropic efficiency & $\eta_{A C}$ & 0.86 \\
GT isentropic efficiency & $\eta_{G T}$ & 0.90 \\
Net power output & $\dot{W}_{\text {Net,GC }}$ & $132,150(\mathrm{~kW})$ \\
Lower heating value & $L H V$ & $49,434(\mathrm{~kJ} / \mathrm{kg})$ \\
cost of fuel & $c_{f u e l}$ & $4.7(\$ / \mathrm{GJ})$ \\
cost of air & $c_{\text {air }}$ & 0 \\
cost of cooling water & $c_{c w}$ & 0 \\
\hline
\end{tabular}

$\mathrm{AC}$, air compressor; GT, gas turbine.

Table 2. Technical input data of the steam turbine cycle.

\begin{tabular}{ccc}
\hline Input Parameter & Symbol & Value (Unit) \\
\hline High-pressure level & $P_{H P}$ & $9600(\mathrm{kPa})$ \\
Low-pressure level & $P_{L P}$ & $1000(\mathrm{kPa})$ \\
Condenser pressure & $P_{\text {cond }}$ & $21.3(\mathrm{kPa})$ \\
Cooling water temperature rise & $\Delta T_{\text {cooling }}$ & $25\left({ }^{\circ} \mathrm{C}\right)$ \\
HPEV pinch temperature difference & $\Delta T_{H P E V}$ & $3\left({ }^{\circ} \mathrm{C}\right)$ \\
LPEV pinch temperature difference & $\Delta T_{L P E V}$ & $41.8\left({ }^{\circ} \mathrm{C}\right)$ \\
ST isentropic efficiency & $\eta_{S T}$ & 0.85 \\
Pump isentropic efficiency & $\eta_{\text {pump }}$ & 0.8 \\
\hline
\end{tabular}

HPEV, high-pressure evaporator; LPEV, LPEV, low-pressure evaporator; ST, steam turbine. 
Multi-effect desalination systems are composed by several identical desalination effects. Therefore, there are several identical devices that are used many times. For modelling purposes, each device is modelled separately in this study. Then, the overall model of the system is thermodynamically analyzed by providing a suitable equation to connect its different parts. The input data for the thermodynamic modelling of the MED unit is given in Table 3 .

Table 3. Technical input data of multi-effect distillation with thermal vapor compression (MED) unit [19].

\begin{tabular}{ccc}
\hline Input Parameter & Symbol & Value (Unit) \\
\hline Number of effects & $n$ & 6 \\
Distillate rate & $\dot{m}_{D}$ & $20(\mathrm{~kg} / \mathrm{s})$ \\
Steam saturation temperature & $T_{S}$ & $70\left({ }^{\circ} \mathrm{C}\right)$ \\
Seawater salinity & $X_{S W}$ & $35(\mathrm{~g} / \mathrm{kg})$ \\
Terminal temperature difference & $\Delta T_{T E R}$ & $2\left({ }^{\circ} \mathrm{C}\right)$ \\
Recovery ratio & $R R$ & 0.3 \\
Last effect temperature & $T_{e f f \_}$ & $48\left({ }^{\circ} \mathrm{C}\right)$ \\
Seawater temperature rise in MED condenser & $\Delta T_{S W}$ & $24\left({ }^{\circ} \mathrm{C}\right)$ \\
Steam returned pressure & $P_{S r}$ & $490(\mathrm{kPa})$ \\
Distillate delivered pressure & $P_{D}$ & $450(\mathrm{kPa})$ \\
\hline
\end{tabular}

The following assumptions are considered to simplify the mathematical modelling approach [19]:

i. The operating conditions of the desalination plant are considered to be steady-state.

ii. The heat transfer plates are large enough to convert all vapor into a saturated liquid according to the operating pressure of each effect.

iii. Seawater is incompressible, and its properties can be expressed as a function of only temperature and salinity.

iv. Energy losses to the environment are negligible.

v. The outlet temperature of brine and freshwater from each MED desalination effect are equal to the temperature of the corresponding effect.

The number of equations which need to be solved simultaneously is quite large. Additionally, the user determines the number of effects which varies the size of equations system. In order to reduce complexity, the simulation of the MED unit is performed via EES software. However, the remaining components of the integrated CCPP and MED-RO desalination system are modelled and solved in MATLAB software. The main thermodynamic governing equations of MED and RO processes are presented in Tables A1 and A2 (see Appendix A), respectively. The thermo physical properties of water and steam streams have been determined using IAPWS [20]. Properties of gaseous streams can be obtained using correlations presented by Dincer et al. [21] and Valero et al. [22]. Additionally, data bank of EES software provides the thermo physical properties of brine streams.

\subsection{Conventional Exergy Analysis}

Exergy is defined as the useful part of energy which is capable to produce work. This parameter provides the basis for many studies by quantifying energy quality. An energy flow can have a large energy amount but low or even zero quality value. For example, the heat that exists at ambient temperature and pressure has zero quality, owing to its inability to produce work. Therefore, the concept of exergy adds a valuable and useful view to thermodynamic studies. Any flow or fluid has an amount of exergy. Each fluid has a potential exergy due to its material and nature, which is called chemical exergy. In this study, the physical and chemical exergy values of each process stream are estimated 
by Equations (1) and (2), respectively. The specific chemical exergy for methane can be calculated by Equation (3) as follows [18].

$$
\begin{gathered}
e x^{P H}=\left(h-h_{0}\right)-T_{0}\left(s-s_{0}\right) \\
e x^{C H}=\sum x_{k} e \bar{x}_{k}^{C H}+\bar{R} T_{0} \sum x_{k} \ln \left(x_{k}\right) \\
e x_{\text {methane }}^{C H}=1.037 \times L H V_{\text {methane }}
\end{gathered}
$$

The chemical exergy associated with seawater streams in $\mathrm{kJ} / \mathrm{kmol}$ (molar basis) is obtained by Equation $(4)[23,24]$ :

$$
e \bar{x}_{s w}^{C H}=n_{s}\left(\bar{\mu}_{s}-\bar{\mu}_{s}^{0}\right)-n_{w}\left(\bar{\mu}_{w}-\bar{\mu}_{w}^{0}\right)
$$

In which, $n_{s}$ and $n_{w}$ indicate the moles number of salt and water in seawater, respectively. Additionally, $\bar{\mu}_{s}$ is the molar chemical potential related to salt in seawater $(\mathrm{kJ} / \mathrm{kmol})$, and $\bar{\mu}_{w}$ is that of water $(\mathrm{kJ} / \mathrm{kmol})$. The superscript zero determines the dead state as indicated by $\bar{\mu}^{0}=f\left(P_{0}, T_{0}\right.$, salinity $)$, and salinity salinity $_{\text {feed }}$.

The chemical exergy related to seawater streams can be estimated by Equation (5) as follows $(\mathrm{kJ} / \mathrm{kg})[23,24]$ :

$$
e x_{s w}^{C H}=m f_{s}\left(\mu_{s}^{*}-\mu_{s}^{0}\right)-m f_{w}\left(\mu_{w}^{*}-\mu_{w}^{0}\right)
$$

In which, $m f_{s}$ and $m f_{w}$ are the mass fraction of salt and water in seawater, respectively. Moreover, $\mu^{*}{ }_{s}$ and $\mu^{*}{ }_{w}$ are the chemical potential associated with salt and water in seawater $(\mathrm{kJ} / \mathrm{kg})$, correspondingly. The superscript ${ }^{*}$ indicates the restricted dead state so that $\mu^{*}=f\left(P_{0}, T_{0}\right.$, salinity i-th stream $)$.

The overall exergy of each stream is obtained as follows [18,21]:

$$
e x_{i}=e x_{i}^{C H}+e x_{i}^{P H}
$$

The exergy rate of each stream can be calculated by Equation (7) $[18,21]$.

$$
\dot{E} x_{i}=\dot{m}_{i} \cdot e x_{i}
$$

One of the important concepts of exergy analysis is the exergy destruction parameter, which is defined as the irreversibility rate of the system. In the ideal and reversible systems, the total inlet and outlet exergy flows of the system are equal. However, in real systems with irreversibility effects such as chemical reactions, transient heating, friction, etc., the total exergy of the output flows from the system is lower than the total exergy of the input flows to the system, which is presented as the exergy destruction of that system. The exergy destruction rate and exergy efficiency of each equipment can be obtained by Equations (8) and (9), respectively [18,21].

$$
\begin{gathered}
\dot{E} x_{D, k}=\dot{E} x_{F, k}-\dot{E} x_{P, k} \\
\varepsilon_{k}=\frac{\dot{E} x_{P, k}}{\dot{E} x_{F, k}}
\end{gathered}
$$

The mathematical formulation for obtaining the exergy destruction of each component in the integrated system is presented in Table 4. 
Table 4. Exergy destruction formulation for different system components.

\begin{tabular}{cc}
\hline System Component & Exergy Destruction Equation \\
\hline AC & $\dot{W}_{A C}-E x_{2}+E x_{1}$ \\
GT & $E x_{3}-E x_{4}-\dot{W}_{G T}$ \\
ST & $E x_{32}+E x_{26}-E x_{16}-\dot{W}_{S T}$ \\
CC & $E x_{F}+E x_{2}-E x_{3}$ \\
Condenser & $E x_{16}-E x_{17}-E x_{C W}$ out $+E x_{C W_{-} \text {in }}$ \\
MED & $E x_{33}+E x_{35}-E x_{34}-E x_{36}-E x_{37}-E x_{38}$ \\
RO & $E x_{36}+\dot{W}_{R O_{-} p u m p}-E x_{39}$ \\
Condenser Pump & $\dot{W}_{C O N D_{-} p u m p}-E x_{19}+E x_{18}$ \\
\hline
\end{tabular}

AC, air compressor; CC, combustion chamber; GT, gas turbine; MED, multi-effect distillation; $R O$, reverse osmosis; $\mathrm{ST}$, steam turbine.

\subsection{Conventional Exergoeconomic Analysis}

In the exergoeconomic modelling and evaluation, expenditures are related to each exergy stream. Table A3 shows the capital investment of each system component (see the Appendix A).

The cost rate of the equipment can be obtained by Equation (10) [21].

$$
\dot{Z}_{k}=\frac{\Phi_{k} \cdot P E C_{k} \cdot C R F}{3600 \cdot N}
$$

In which, $\Phi_{k}$ indicates the maintenance factor (equal to 1.06 in this work $[18,21]$ ), while $N$ is the annual operating hours $(8000 \mathrm{~h})[18,21]$, and $C R F$ is the capital recovery factor as given by [18]:

$$
C R F=\frac{i \cdot(1+i)^{n y}}{(1+i)^{n y}-1}
$$

In Equation (11), $i$ represents the interest rate and $n y$ the plant lifetime (25 years) $[18,21]$. The exergoeconomic balance formulation is expressed as follows [18].

$$
\begin{gathered}
\dot{C}_{P, k}=\dot{C}_{F, k}-\dot{C}_{L, k}+\dot{Z}_{k} \\
\sum_{e} \dot{C}_{e, k}+\dot{C}_{w, k}=\dot{C}_{q, k}-\sum_{i} \dot{C}_{i, k}+\dot{Z}_{k} \\
\dot{C}_{i}=c_{i} \cdot \dot{E} x_{i}
\end{gathered}
$$

The exergy cost of destruction of each system component is given as follows [18].

$$
\dot{C}_{D, k}=c_{F, k} \cdot \dot{E} x_{D, k}
$$

The exergoeconomic factor for each equipment can be estimated by Equation (16) [18].

$$
f_{k}=\frac{\dot{Z}_{k}}{\dot{Z}_{k}+c_{f, k} \cdot \dot{E} x_{D, k}}
$$

The relative cost difference can be obtained by the following equation [18].

$$
r_{k}=\frac{c_{P, k}-c_{F, k}}{c_{F, k}}=\frac{1-\varepsilon_{k}}{\varepsilon_{k}}+\frac{\dot{Z}_{k}}{c_{f, k} \cdot \dot{E} x_{P, k}}
$$




\subsection{Conventional Exergoenvironmental Analysis}

The exergoenvironmental analysis consists of three phases. First, exergy analysis is carried out for each process stream. Then, the environmental impacts of the manufacturing process are estimated for each component. Finally, the exergoenvironmental equations are implemented to predict the environmental impact of each stream based on the exergy analysis. The exergoenvironmental analysis for each equipment is performed via the following formulation [25].

$$
\begin{gathered}
\dot{B}_{P, k}=\dot{B}_{F, k}-\dot{B}_{L, k}+\dot{Y}_{k} \\
\sum_{e} \dot{B}_{e, k}+\dot{B}_{w, k}=\dot{B}_{q, k}-\sum_{i} \dot{B}_{i, k}+\dot{Y}_{k} \\
\dot{B}_{i}=b_{i} \cdot \dot{E} x_{i}
\end{gathered}
$$

The environmental impact rate associated with the exergy destruction of each system component is given by Equation (21) [25].

$$
\dot{B}_{D, k}=b_{F, k} \cdot \dot{E} x_{D, k}
$$

The exergoenvironmental factor for each equipment can be calculated by Equation (22) [25].

$$
f b_{k}=\frac{\dot{Y}_{k}}{\dot{Y}_{k}+b_{f, k} \cdot \dot{E} x_{D, k}}
$$

The relative environmental impact difference is determined as follows [25].

$$
r b_{k}=\frac{b_{P, k}-b_{F, k}}{b_{F, k}}=\frac{1-\varepsilon_{k}}{\varepsilon_{k}}+\frac{\dot{Y}_{k}}{b_{f, k} \cdot \dot{E} x_{P, k}}
$$

The environmental impact of each equipment can be obtained by Equation (24) [25]:

$$
y_{k}=w_{k} \cdot b m_{k}
$$

In which, $y_{k}$ is the environmental impact of the equipment in points (pts), while $w_{k}$ is the weight of the equipment in tons. $b m_{k}$ represents the environmental impact per mass unit of the equipment in pts/ton, which is a function of the material used in the manufacturing process of the different system components. The latter can be obtained from the Eco-indicator 99 methodology through the determination of the material composition related to each component [26]. The weight function associated with each equipment unit is given in Table 5 .

The environmental impact rate of the $\mathrm{RO}$ unit in $\mathrm{mpts} /\left(\mathrm{h} \mathrm{m}^{3}\right)$ is estimated by the following equation [27]:

$$
\dot{Y}_{R O}=0.0195 \frac{\rho \cdot \dot{W}_{R O}}{3600 \cdot \dot{m}_{R O-\text { distillate }}}+0.00595
$$

The environmental impact rate of the MED unit is equal to $\dot{Y}_{M E D}=1.277 \mathrm{mpts} /\left(\mathrm{h} \mathrm{m}^{3}\right)$ [27]. In addition, as input information is required for solving the problem, the environmental impacts of the equipment weight unit are listed in Table 6. 
Table 5. Weight function associated with each system component [25].

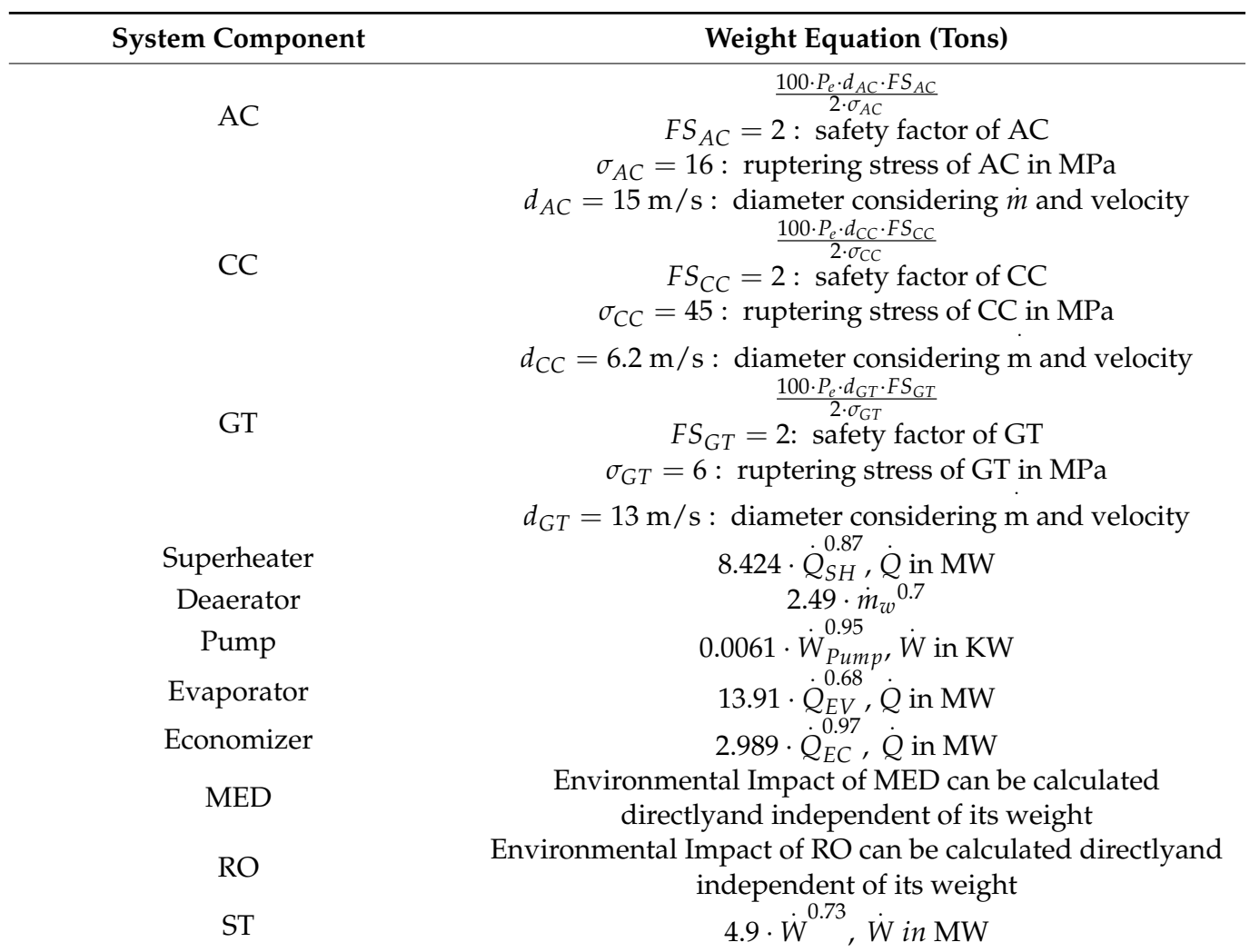

$\overline{\mathrm{AC}}$, air compressor; $\mathrm{CC}$, combustion chamber; GT, gas turbine; MED, multi-effect distillation; RO, reverse osmosis, ST, steam turbine.

Table 6. Environmental impacts of the equipment weight unit.

\begin{tabular}{ccc}
\hline System Component & Composition & b $_{\boldsymbol{k}}$ (pts/ton) \\
\hline AC & Steel 33.33\%, steel low alloy & 71.7 \\
& $44.5 \%$, cast iron 22.22\% & \\
CC & Steel 33.34\%, steel high alloy & 585.0 \\
GT & 66.66\% & 645.7 \\
Superheater & Steel 25\%, steel high alloy 75\% & 638.0 \\
Evaporator & Steel 26\%, steel high alloy 74\% & 28.0 \\
Economizer & Steel 100\% & 28.0 \\
Pump & Steel 100\% & 132.8 \\
Condenser & Steel 35\%, cast iron 65\% & 28.0 \\
ST & Steel 100\% & 646 \\
\hline
\end{tabular}

$\mathrm{AC}$, air compressor; $\mathrm{CC}$, combustion chamber; GT, gas turbine; ST, steam turbine.

\subsection{Advanced Exergy Analysis}

Exergy analysis has two important indicators that provide a relative understanding of process energy performance: exergy destruction and exergy efficiency. These two indicators of exergy analysis show how a device works in terms of quality of energy consumption. They also allow to determine which equipment does not have good exergy performance, and wastes useful work in a process. Advanced exergy analysis is based on the results of the exergy analysis. Therefore, the input data of the advanced analysis are the irreversibility and efficiency of the related process equipment. The main idea behind the advanced exergy analysis is the irreversible division of a system device. Irreversibility that occurs in a device is not only due to the thermodynamic malfunction of the equipment itself, but also to the performance of other components in which it is associated with in the process. Although the exergy analysis can be used to determine the irreversibilities of a device in a more 
accurately and easily way, it is not able to classify such irreversibilities regarding their origin [17]. In other words, conventional exergy analysis is unable to determine the device irreversibilities originated by other means than the function of the device itself. However, this can be done by an advanced exergy analysis. In this type of analysis, equipment irreversibility is divided into two perspectives: one from the origin of irreversibility, and another from the ability to eliminate such irreversibility. From the origin point of view, the irreversibility of each device is divided into two categories: endogenous and exogenous irreversibility. Still, from the ability to eliminate perspective, the irreversibility of each device is classified as avoidable and unavoidable [28]. The advanced energy analysis is presented in the following sections.

\subsubsection{Endogenous and Exogenous Irreversibility}

In a system with $n$ elements, the endogenous exergy destruction of the $k$-th element is that part of the exergy destruction that depends on the irreversibility of that component itself. The destruction of endogenous exergy is achieved when the element operates in real conditions, whereas other elements operate in theoretical conditions and without any irreversibility. Equation (26) indicates the relation between endogenous, exogenous, and real exergy destruction for component $k$ [29].

$$
\dot{E} x_{D, k}^{E X}=\dot{E} x_{D, k}^{r e a l}-\dot{E} x_{D, k}^{E N}
$$

\subsubsection{Avoidable and Unavoidable Irreversibility}

The part of exergy destruction that cannot be avoided by changes in system design technology to improve its thermodynamic and physical conditions is called avoidable exergy destruction. These conditions are provided when the destruction tends to be the minimum value, and the temperature differences and pressure drop in the elements are as low as possible. In many studies, the conditions applied to the unavoidable state are suggested by the author's knowledge and experience on the possibility of maximizing the potential of the element to be improved. After estimating the unavoidable exergy destruction, the amount of avoidable exergy destruction is calculated as follows [29].

$$
\dot{E} x_{D, k}^{A V}=\dot{E} x_{D, k}^{r e a l}-\dot{E} x_{D, k}^{U N}
$$

3.5.3. Combination of Endogenous/Exogenous and Avoidable/Unavoidable Irreversibility

The avoidable exergy destruction is divided into endogenous and exogenous categories. Endogenous avoidable exergy destruction is the part of exergy destruction that occurs due to the irreversibility of the elements themselves and can be avoided. Therefore, with the improvement of the efficiency of this element, the amount of its endogenous exergy destruction will be reduced. Exogenous avoidable exergy destruction is also caused by irreversibility in other elements, but because it is avoidable, the exogenous avoidable exergy destruction can be reduced by improving the efficiency of other elements of the cycle. On the other hand, the endogenous and exogenous unavoidable exergy destruction are caused by the limitations of the element's technology, as well as the irreversible effect and technological limitations of other elements. The endogenous and exogenous unavoidable exergy destruction for the elements are estimated as follows:

$$
\begin{gathered}
\dot{E} x_{D, k}^{U N, E N}=\dot{E} x_{p, k}^{E N}\left(\dot{E} x_{D} / \dot{E} x_{P}\right)_{k}^{U N} \\
\dot{E} x_{D, k}^{U N, E X}=\dot{E} x_{D, k}^{U N}-\dot{E} x_{D, k}^{U N, E N}
\end{gathered}
$$

Endogenous avoidable exergy destruction and exogenous avoidable exergy destruction are obtained by subtracting endogenous unavoidable and exogenous unavoidable 
exergy destruction, from endogenous exergy destruction and exogenous exergy destruction, respectively, as follows:

$$
\begin{aligned}
& \dot{E} x_{D, k}^{A V, E N}=\dot{E} x_{D, k}^{E N}-\dot{E} x_{D, k}^{U N, E N} \\
& \dot{E} x_{D, k}^{A V, E X}=\dot{E} x_{D, k}^{E X}-\dot{E} x_{D, k}^{U N, E X}
\end{aligned}
$$

Therefore, the exergy destruction of the $k$-th element can be written as follows:

$$
\dot{E} x_{D, k}^{r e a l}=\dot{E} x_{D, k}^{U N, E N}+\dot{E} x_{D, k}^{U N, E X}+\dot{E} x_{D, k}^{A V, E N}+\dot{E} x_{D, k}^{A V, E X}
$$

\subsection{Advanced Exergoeconomic Analysis}

Similarly to the previous discussions on advanced exergy analysis, in advanced exergoeconomic analysis, the cost of exergy destruction of each component is divided into four parts: endogenous, exogenous, avoidable, and unavoidable cost of exergy destruction [29].

\subsubsection{Endogenous and Exogenous Cost of Exergy Destruction}

The endogenous cost of exergy destruction is the part of the exergy destruction cost that depends on the performance of the $k$-th element itself, the internal irreversibility of this element, and the average fuel cost per exergy unit of the component. The exogenous cost rate of exergy destruction is also the part of the exergy destruction cost that is exerted by the other elements on the $k$-th element. The rate of endogenous exergy destruction is obtained by implementing real conditions to the element itself, and theoretical conditions to other elements. The endogenous cost rate of exergy destruction and the exogenous cost rate of exergy destruction are obtained as follows [30].

$$
\begin{aligned}
& \dot{C}_{D, k}^{E N}=c_{F, k} \cdot \dot{E} x_{D, k}^{E N} \\
& \dot{C}_{D, k}^{E X}=c_{F, k} \cdot \dot{E} x_{D, k}^{E x}
\end{aligned}
$$

Therefore, the total cost of exergy destruction in both endogenous and exogenous states is equal to the total cost of exergy destruction:

$$
\dot{C}_{D, k}^{\text {real }}=c_{F, k} \cdot \dot{E} x_{D, k}^{r e a l}=\dot{C}_{D, k}^{E N}+\dot{C}_{D, k}^{E X}
$$

\subsubsection{Avoidable and Unavoidable Cost of Exergy Destruction}

The rate of the cost of exergy destruction in the avoidable and unavoidable conditions is given by the following equations.

$$
\begin{aligned}
& \dot{C}_{D, k}^{U N}=c_{F, k} \cdot \dot{E} x_{D, k}^{U N} \\
& \dot{C}_{D, k}^{A V}=c_{F, k} \cdot \dot{E} x_{D, k}^{A V}
\end{aligned}
$$

The cost rate of unavoidable exergy destruction is the cost of the fuel required to provide avoidable exergy destruction in the component, while the product exergy of the component is considered to be constant. Additionally, the sum of the avoidable and unavoidable exergy destruction cost rate is equal to the total cost rate of exergy destruction of the component, as shown as follows:

$$
\dot{C}_{D, k}^{\text {real }}=c_{F, k} \cdot \dot{E} x_{D, k}^{r e a l}=\dot{C}_{D, k}^{U N}+\dot{C}_{D, k}^{A V}
$$


3.6.3. Combination of Endogenous/Exogenous and Avoidable/Unavoidable Cost of Exergy Destruction

The combination of the cost of exergy destruction into different sections can be written as follows:

$$
\begin{aligned}
& \dot{C}_{D, k}^{E N, A V}=c_{F, k} \cdot \dot{E} x_{D, k}^{E N, A V} \\
& \dot{C}_{D, k}^{E N, U N}=c_{F, k} \cdot \dot{E} x_{D, k}^{E N, U N} \\
& \dot{C}_{D, k}^{E X, A V}=c_{F, k} \cdot \dot{E} x_{D, k}^{E X, A V} \\
& \dot{C}_{D, k}^{E X, U N}=c_{F, k} \cdot \dot{E} x_{D, k}^{E X, U N}
\end{aligned}
$$

In Equation (39), $\dot{C}_{D, k}^{E N, A V}$ indicates the cost rate of endogenous avoidable exergy destruction of the $k$-th element, which depends on the performance of the element itself. Therefore, by optimizing the condition of this element, its amount can be improved. In Equation (41), $\dot{C}_{D, k}^{E X, A V}$ is the cost rate of exogenous avoidable exergy destruction of the $k$-th element, which can be improved by optimizing the conditions of other elements of the cycle. $\dot{C}_{D, k}^{E N, U N}$ and $\dot{C}_{D, k}^{E X, U N}$ are the cost rate of endogenous unavoidable exergy destruction, and the cost rate of exogenous unavoidable exergy destruction of the $k$-th component, respectively.

\subsection{Advanced Exergoenvironmental Analysis}

Similarly to the discussions on advanced exergy analysis, in advanced exergoenvironmental analysis, the environmental impact of exergy destruction of each component is divided into four parts: endogenous, exogenous, avoidable, and unavoidable environmental impact of exergy destruction [31].

\subsubsection{Endogenous and Exogenous Environmental Impact of Exergy Destruction}

The endogenous environmental impact of exergy destruction is the part of the exergy destruction environmental impact that depends on the performance of the $k$-th element itself, the internal irreversibility of this element, and the average fuel environmental impact per exergy unit of the component. The exogenous environmental impact rate of exergy destruction is also the part of the exergy destruction environmental impact that is exerted by the other elements on the $k$-th element. The rate of endogenous exergy destruction is obtained by implementing real conditions to the element itself, and theoretical conditions to other elements. The endogenous environmental impact rate of exergy destruction and the exogenous environmental impact rate of exergy destruction are obtained as follows [30].

$$
\begin{aligned}
& \dot{B}_{D, k}^{E N}=b_{F, k} \cdot \dot{E} x_{D, k}^{E N} \\
& \dot{B}_{D, k}^{E X}=b_{F, k} \cdot \dot{E} x_{D, k}^{E X}
\end{aligned}
$$

Therefore, the total environmental impact of exergy destruction in both endogenous and exogenous states is equal to the total environmental impact of exergy destruction.

$$
\dot{C}_{D, k}^{\text {real }}=c_{F, k} \cdot \dot{E} x_{D, k}^{r e a l}=\dot{C}_{D, k}^{E N}+\dot{C}_{D, k}^{E X}
$$

\subsubsection{Avoidable and Unavoidable Environmental Impact of Exergy Destruction}

The rate of the environmental impact of exergy destruction in the avoidable and unavoidable conditions are given by the following equations:

$$
\dot{B}_{D, k}^{U N}=b_{F, k} \cdot \dot{E} x_{D, k}^{U N}
$$




$$
\dot{B}_{D, k}^{A V}=b_{F, k} \cdot \dot{E} x_{D, k}^{A V}
$$

The environmental impact rate of unavoidable exergy destruction refers to the environmental impact of the fuel required to provide avoidable exergy destruction in the component, while the product exergy of the component is considered to be constant. Additionally, the sum of the avoidable and unavoidable exergy destruction environmental impact rate is equal to the total environmental impact rate of exergy destruction of the component, as shown as follows:

$$
\dot{B}_{D, k}^{\text {real }}=b_{F, k} \cdot \dot{E} x_{D, k}^{r e a l}=\dot{B}_{D, k}^{U N}+\dot{B}_{D, k}^{A V}
$$

3.7.3. Combination of Endogenous/Exogenous and Avoidable/Unavoidable Environmental Impact of Exergy Destruction

The combination of the environmental impact of exergy destruction into different sections can be written as follows:

$$
\begin{aligned}
& \dot{C}_{D, k}^{E N, A V}=c_{F, k} \cdot \dot{E} x_{D, k}^{E N, A V} \\
& \dot{C}_{D, k}^{E N, U N}=c_{F, k} \cdot \dot{E} x_{D, k}^{E N, U N} \\
& \dot{C}_{D, k}^{E X, A V}=c_{F, k} \cdot \dot{E} x_{D, k}^{E X, A V} \\
& \dot{C}_{D, k}^{E X, U N}=c_{F, k} \cdot \dot{E} x_{D, k}^{E X, U N}
\end{aligned}
$$

In Equation (49), $\dot{C}_{D, k}^{E N, A V}$ represents the environmental impact rate of endogenous avoidable exergy destruction of the $k$-th element, which depends on the performance of the element itself. Therefore, by optimizing the condition of this element, its amount can be improved. In Equation (51), $\dot{C}_{D, k}^{E X, A V}$ indicates the environmental impact rate of exogenous avoidable exergy destruction of the $k$-th element, which can be improved by optimizing the conditions of other elements of the cycle. $\dot{C}_{D, k}^{E N, U N}$ and $\dot{C}_{D, k}^{E X, U N}$ are the environmental impact rate of endogenous unavoidable exergy destruction, and the environmental impact rate of exogenous unavoidable exergy destruction of the $k$-th component, respectively.

\section{Results and Discussion}

\subsection{Validation of Thermodynamic Results}

Table 7 presents the verification of the MATLAB thermodynamic simulation results obtained for the $\mathrm{RO}$ desalination unit in comparison with other studies from the literature. The results show a good agreement with those attained by Al-Zahrani et al. [3] and Zhou et al. [32]. Table 8 displays the validation of the thermodynamic simulation results obtained for the MED unit via the Thermoflex software. Overall, the MED results also show good agreement with those from the thermodynamic modelling in Thermoflex (which is based on real plant data) with errors lower than $4 \%$. In Tables A4 and A5 (see Appendix A), the main process parameters obtained from thermodynamic modelling in Thermoflex, and the proposed MATLAB modelling approach are compared for the different process streams and system components, respectively. As it is shown, the results of thermodynamic simulation in MATLAB and Thermoflex software are also in an appropriate agreement with each other. 
Table 7. Comparison of the obtained reverse osmosis (RO) simulation results with the literature.

\begin{tabular}{cccc}
\hline $\begin{array}{c}\text { Thermodynamic } \\
\text { Parameters (Unit) }\end{array}$ & $\begin{array}{c}\text { Present Study } \\
\text { (MATLAB) }\end{array}$ & Al-Zahrani et al. [3] & Zhou et al. [32] \\
\hline Feed Pressure (bar) & 50 & 50 & 50 \\
Feed Salinity (\%) & 3 & 3 & 3 \\
Recovery Ratio & 0.5008 & 0.51 & 0.481 \\
\hline
\end{tabular}

Table 8. Validation of the multi-effect desalination (MED) results obtained by the proposed approach.

\begin{tabular}{cccc}
\hline $\begin{array}{c}\text { Thermodynamic } \\
\text { Parameters (Unit) }\end{array}$ & $\begin{array}{c}\text { Present Study } \\
\text { (MATLAB) }\end{array}$ & Thermoflex & Error (\%) \\
\hline No. of effects & 6 & 6 & 0.000 \\
GOR & 5.41 & 5.32 & 1.69 \\
SA & 321.89 & 332.1 & 3.07 \\
$\dot{m}_{\text {steam }}(\mathrm{kg} / \mathrm{s})$ & 3.28 & 3.22 & 1.86 \\
$\dot{m}_{\text {distillate }}(\mathrm{kg} / \mathrm{s})$ & 20.00 & 20.00 & 0.00 \\
\hline
\end{tabular}

The results obtained from thermodynamic modelling of the existing combined cycle of Neka power plant indicate the consumption of $8.43 \mathrm{~kg}$ of fuel per second to simultaneously produce $132.15 \mathrm{MW}$ of gas power, and $80 \mathrm{MW}$ of steam power. To integrate the existing Neka power cycle with MED-RO desalination systems, a stream is extracted from the low-pressure section of the combined cycle to satisfy the stimulus vapor of the multi-effect desalination water with a mass flowrate of $3.6 \mathrm{~kg} / \mathrm{s}$. Additionally, the mass flowrate output of the cooling water section of the MED desalination plant is used as the inlet flow of the $\mathrm{RO}$ desalination section. The multi-effect thermal desalination unit produces around $20 \mathrm{~kg}$ of freshwater per second from an inlet seawater mass flowrate of about $12.48 \mathrm{~kg} / \mathrm{s}$. The $\mathrm{RO}$ desalination unit is capable of producing $6.54 \mathrm{~kg}$ of freshwater per second. Moreover, the calculations performed on the proposed integrated water and power cycle indicates a $3.79 \%$ increase in fuel consumption compared to the conditions before the integration. The thermodynamic calculations of the proposed integrated cycle also show that total power production of the plant is reduced by $19 \%$, in order to produce $26.54 \mathrm{~kg}$ of freshwater per second. Under these conditions, the energy efficiency of the Neka power plant decreases by $2.49 \%$ (from $47.98 \%$ to $45.49 \%$ ) after the integration with desalination units.

\subsection{Conventional Exergy, Exergoeconomic, and Exergoenvironmental Results}

After modelling the integrated system and implementing conventional exergy, exergoeconomic, and exergoenvironmental analyses, different parameters are estimated for each of the process streams and components. Table A6 (see Appendix A) shows the results of thermodynamic, exergy, economic, and environmental analyses for each stream in the system. The corresponding results obtained for different system components are presented in Table 9. The results presented in Table 9 reveal that the exergy efficiencies of the MED $(31.59 \%)$ and $\mathrm{RO}(19.51 \%)$ desalination units, and condensers (34.56\%) are relatively lower when compared to other components. The GT unit presents the highest exergy efficiency of $95.87 \%$. The exergoeconomic efficiencies of the CC $(1.87 \%)$ and condenser $(1.46 \%)$ are relatively lower when compared to other components. This is due to the high cost and environmental effects of exergy degradation on these two components. Thus, these components have great potential to improve the system performance, because their exergy destruction has a significant undesired impact on the environment and costs. Improving these components' performance will obviously come at the expense of a cost increase. In addition, the HRSG $(2.19 \%)$ and condenser $(0.003 \%)$ have comparatively low exergoenvironmental factors, which indicate that the exergy destruction of these components has high adverse effects on the environment. Therefore, it is possible to reduce the exergy destruction of these components for decreasing the environmental impacts of the integrated system. Still, spending cost and improving the performance of the condenser due to its low 
exergy-economic and exergy-environmental coefficients are among the effective proposals to reduce costs and environmental effects of the exergy destruction of this unit.

Table 9. Conventional exergy, economic, and environmental results for different system components.

\begin{tabular}{|c|c|c|c|c|c|c|c|c|}
\hline $\begin{array}{c}\text { System } \\
\text { Component }\end{array}$ & $\begin{array}{c}Z \\
\text { (US\$/h) }\end{array}$ & $f(\%)$ & $r(\%)$ & $\begin{array}{c}\dot{C}_{D} \\
\text { (US\$/h) }\end{array}$ & $\begin{array}{c}\dot{Y} \\
(\mathrm{mpts} / \mathrm{h})\end{array}$ & $f b(\%)$ & $\begin{array}{c}\dot{B}_{D} \\
\text { (pts/h) }\end{array}$ & $\varepsilon(\%)$ \\
\hline $\mathrm{AC}$ & 140.33 & 27.73 & 10.43 & 365.76 & 288.94 & 84.69 & 0.05 & 92.99 \\
\hline $\mathrm{CC}$ & 74.94 & 1.87 & 43.50 & 3925.62 & 1463.62 & 0.06 & 2352.76 & 70.08 \\
\hline GT & 172.63 & 30.77 & 6.22 & 388.46 & 2944.96 & 96.75 & 0.10 & 95.87 \\
\hline Condenser & 79.55 & 1.46 & 11.38 & 462.29 & 6.37 & 0.003 & 224.33 & 34.56 \\
\hline $\mathrm{ST}$ & 6.85 & 15.97 & 189.35 & 418.66 & 1552.86 & 0.64 & 242.26 & 84.96 \\
\hline MED & 12.15 & 7.18 & 237.73 & 117.54 & $92,937.26$ & 56.91 & 52.75 & 31.59 \\
\hline $\mathrm{RO}$ & 38.86 & 82.24 & 479.90 & 8.39 & 2823.66 & 36.49 & 4.91 & 19.51 \\
\hline PRE & 39.58 & 31.68 & 113.22 & 85.36 & 31.65 & 0.06 & 50.88 & 56.38 \\
\hline LPEC & 22.49 & 83.75 & 132.70 & 4.36 & 4.00 & 0.15 & 2.60 & 82.26 \\
\hline HPEC1 & 40.07 & 54.32 & 57.69 & 33.69 & 29.68 & 0.15 & 20.08 & 79.14 \\
\hline LPEV & 35.45 & 46.84 & 38.12 & 40.23 & 65.17 & 0.27 & 23.98 & 83.15 \\
\hline LPSH & 41.40 & 95.42 & 296.14 & 1.99 & 1559.06 & 56.84 & 1.18 & 88.06 \\
\hline HPEC2 & 87.99 & 67.54 & 26.88 & 42.29 & 94.19 & 0.37 & 25.20 & 91.98 \\
\hline HPEV & 107.45 & 47.27 & 19.04 & 119.87 & 175.22 & 0.24 & 71.45 & 90.88 \\
\hline HPSH & 57.58 & 50.96 & 15.89 & 55.40 & 3159.00 & 8.73 & 33.02 & 92.77 \\
\hline HRSG & 432.01 & 52.99 & 25.09 & 383.19 & 5118 & 2.19 & 228.39 & 84.79 \\
\hline
\end{tabular}

AC, air compressor; CC, combustion chamber; GT, gas turbine; ST, steam turbine; MED, Multi Effect Desalination; RO, Reverse Osmosis; PRE, Preheater; LPEC, Low Pressure Economiser; HPEC1, High Pressure Economiser1; LPEV, Low Pressure Evaporator; LPSH, Low Pressure Superheater; HPEC2, High Pressure Economiser2; HPEV, High Pressure Evaporator; HPSH, High Pressure Superheater; HRSG, Heat Recovery Steam Generator.

Table 9 also shows that the relative cost difference of the MED system $(237.73 \%)$ is significantly smaller than that of the RO desalination unit (479.9\%). This observation indicates that the cost of freshwater produced relative to the cost of fuel required for the MED unit, is lower than that of RO desalination unit. Still, according to Table 9, gas turbines present the highest investment cost of 0.047 US\$ per second, while the MED exhibits the highest environmental impact rate of 0.025 points per second. It should also be noted that the cost of exergy destruction and environmental effects imposed by exergy destruction on equipment are higher for the CC, GT, and ST units, when contrasted to other devices. Hence, improvements in the performance of these devices can reduce their exergy destruction and avoid cost wastage, as well as prevent the imposition of environmental effects by exergy destruction. This is because the exergy destruction of these components has higher adverse economic and environmental effects. One of the important outputs of exergy analysis is the distribution of exergy destruction between different parts of the system. Figure 5 depicts the distribution of exergy destruction between the different equipment in the integrated system.

According to Figure 5, the CC exhibits the highest share of exergy destruction (57\%). The GT and HRSG units present $9 \%$ both, while the MED-RO desalination units account for only $2 \%$ of the exergy destruction in the system. Thus, these results reveal that the highest rate of exergy destruction is related to the gas turbine cycle in the CCPP. Therefore, reducing the share of the destruction of the gas turbine cycle can have a positive effect on the destruction of the entire plant. 


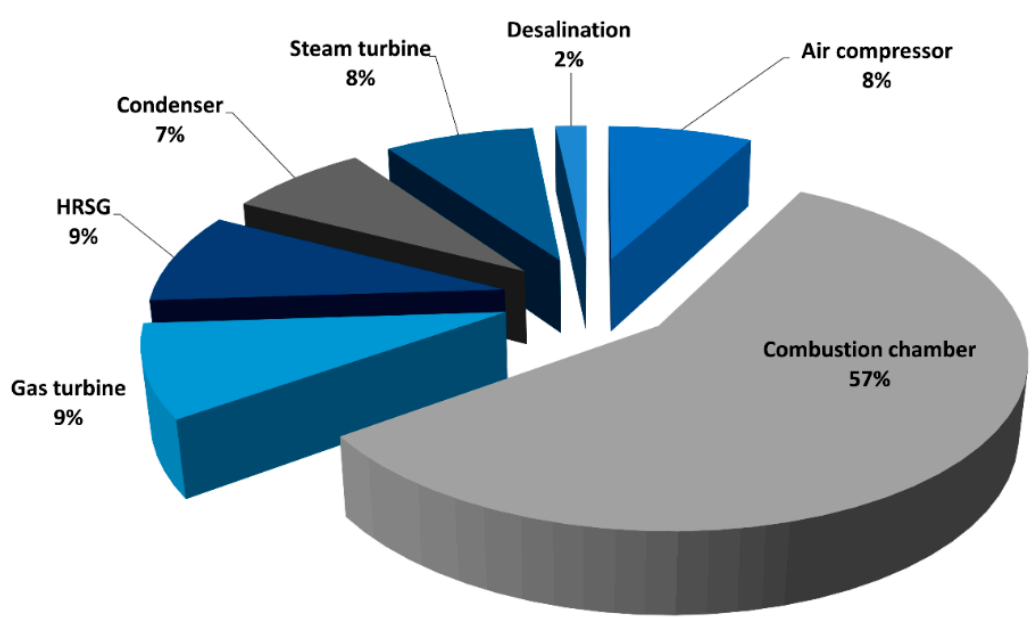

Figure 5. Exergy destruction distribution between the main system components. HRSG, heat recovery steam generator.

\subsection{Advanced Exergy, Exergoeconomic, and Exergoenvironmental Results}

The results of advanced exergy, exergoeconomic, and exergoenvironmental analyses are presented in this section. Figure 6 displays the distributions of the avoidable/unavoidable and endogenous/exogenous exergy destruction for different system components expressed in relative and quantitative values. According to Figure 6a, the highest proportions of avoidable exergy destruction are related to the MED-RO desalination units $(47 \%)$, followed by the HRSG unit $(33.87 \%)$, ST $(22.26 \%)$, and condenser $(21.69 \%)$. Hence, these are the components that have more potential for improvement in order to reduce the exergy destruction of the system. In addition, the highest endogenous exergy degradation portion belongs to the CC $(85.69 \%)$ and ST $(82.36 \%)$, respectively. Therefore, these components have the highest capacity to reduce their exergy destruction and they are the most suitable choices to reduce the exergy destruction among the system components. Figure 6 also reveals that the maximum avoidable fraction (relative value) and maximum avoidable value (quantitative value) can be different in terms of equipment (i.e., the MED-RO desalination units present the maximum avoidable relative value for the exergy destruction, while the $\mathrm{CC}$ unit shows the maximum avoidable quantitative one). In the same way, the equipment with the highest relative value for unavoidable exergy destruction will not necessarily have the highest quantitative value for the unavoidable exergy destruction. According to Figure $6 \mathrm{~b}$, the maximum amount of unavoidable and endogenous exergy destruction is related to the CC unit. Therefore, performance improvements in this equipment can significantly reduce the exergy destruction of the whole system.

Figure 7 shows the distributions of avoidable/unavoidable and endogenous/exogenous exergy destruction costs for different system components expressed in relative and quantitative values. According to Figure 7a, the highest proportions of the cost of avoidable exergy destruction are related to the MED-RO desalination section ( $50.58 \%)$, followed by the HRSG unit (37.87\%), condenser (24.65\%), and ST (20.32\%). Hence, in order to reduce the cost of exergy destruction of different parts of the system, the aforementioned components present higher potential for improvements. In addition, the highest costs of endogenous exergy destruction belong to the CC $(87.32 \%)$ and ST $(86.12 \%)$. Thus, the CC and ST units are the most appropriate choices to reduce the relative cost of exergy destruction among the system components. Figure 7 also reveals that the maximum avoidable relative exergy destruction cost can significantly differ from the maximum avoidable quantitative value in terms of equipment (i.e., the MED-RO desalination units present the maximum avoidable relative value for the exergy destruction cost, while the CC unit shows the maximum avoidable quantitative one). Similarly, the equipment with the highest relative value for unavoidable exergy destruction cost will not necessarily have the highest quantitative value for the unavoidable exergy destruction cost. 


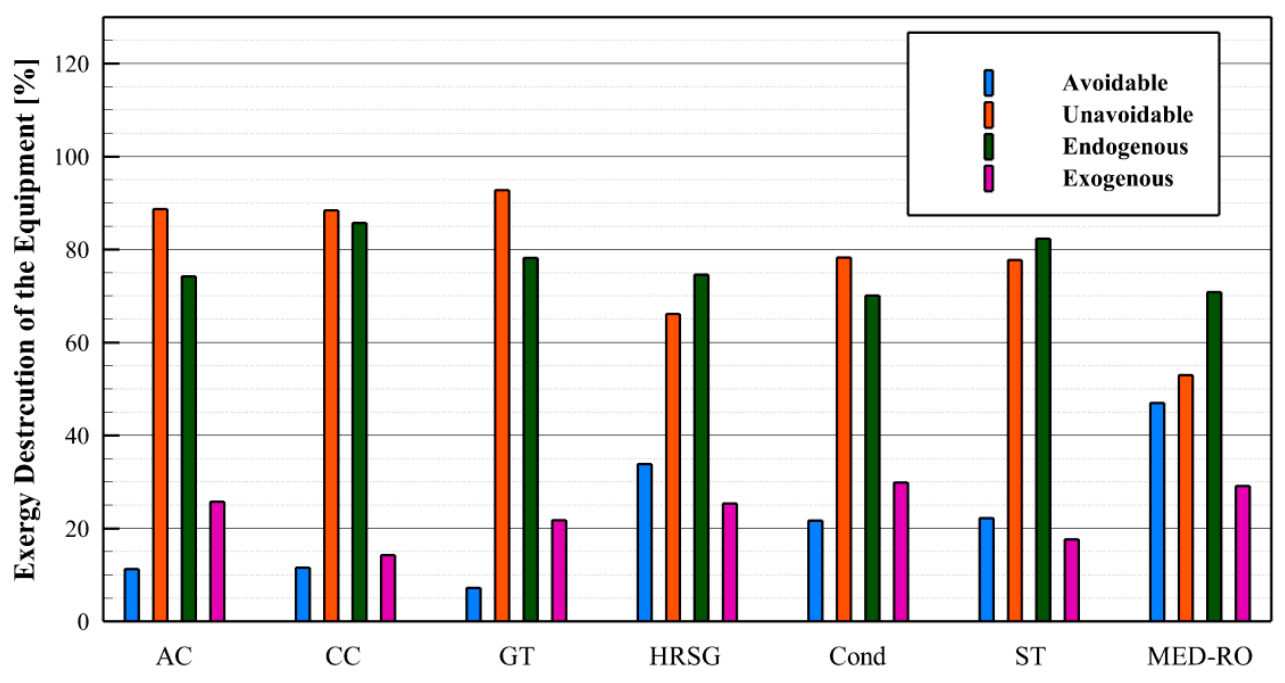

(a)

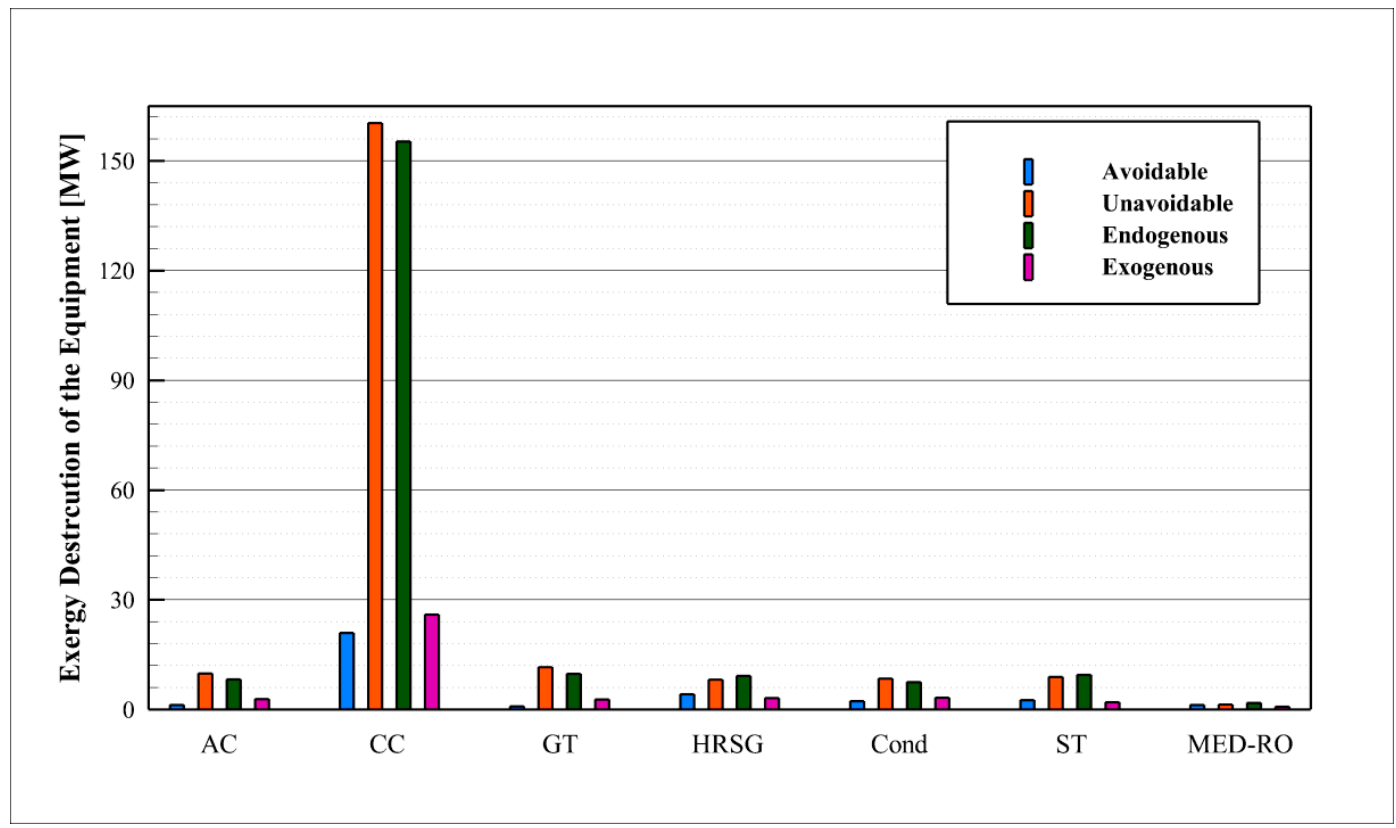

(b)

Figure 6. Distributions of avoidable/unavoidable and endogenous/exogenous exergy destruction for different system components in (a) relative values, and (b) quantitative values. AC, air compressor; CC, combustion chamber; GT, gas turbine; HRSG, heat recovery steam generator; Cond, condenser; ST, steam turbine; MED-RO, multi-effect distillation and reverse osmosis system.

Figure $7 \mathrm{~b}$ shows that the highest cost of avoidable exergy destruction is related to the CC (575.1 US\$/h), followed by the HRSG unit (145.1 US\$/h), condenser (103.2 US $\$ / h)$, and ST unit (93.94 US\$/h). In addition, the CC (3427.8 US\$/h), ST (398.13 US\$/h), condenser (301.94 US\$/h), and HRSG units (294.35 US\$/h) have the highest shares of endogenous exergy destruction cost. Therefore, performance improvements in these equipment units have the greatest potential for reducing the cost of exergy destruction of the whole system. 


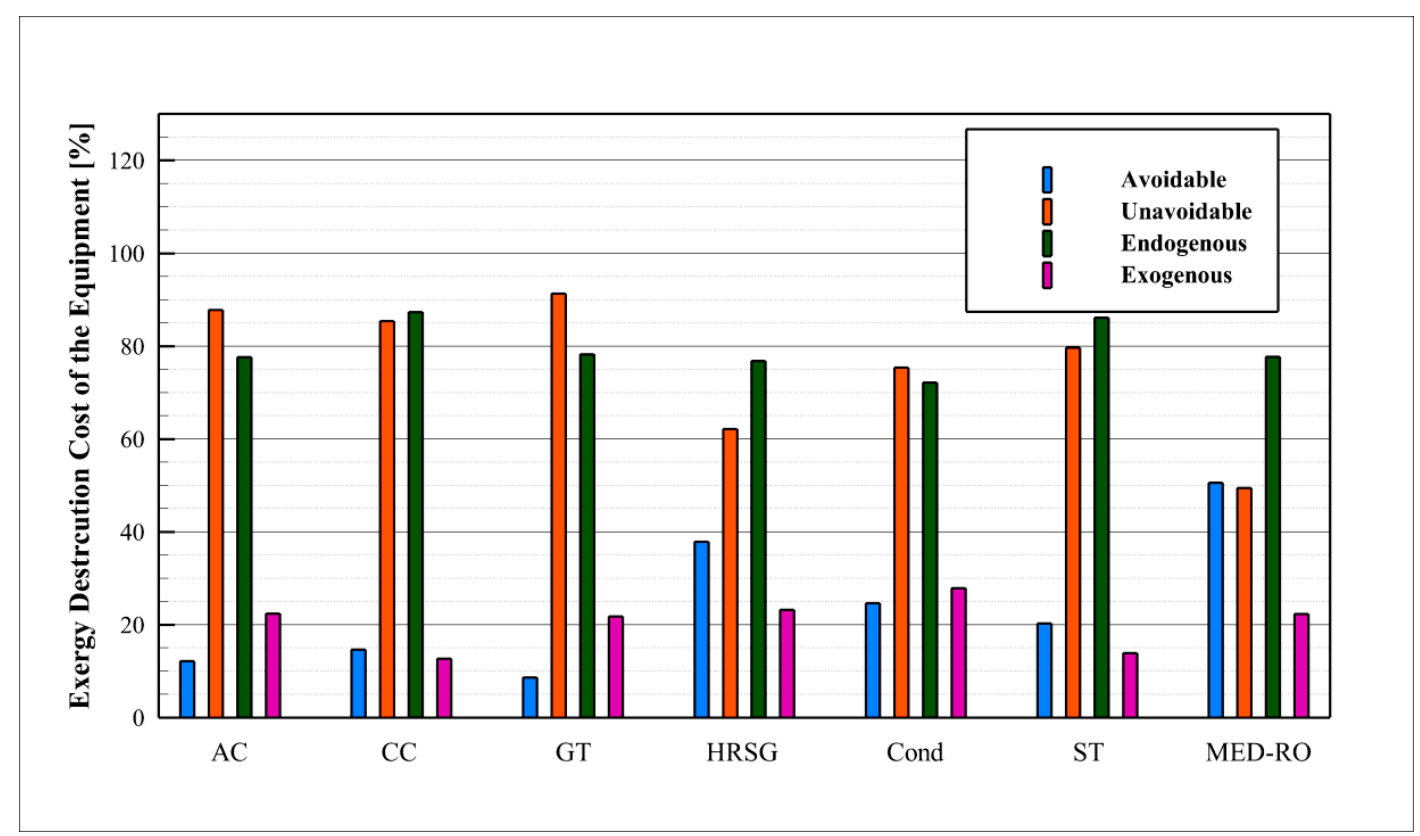

(a)

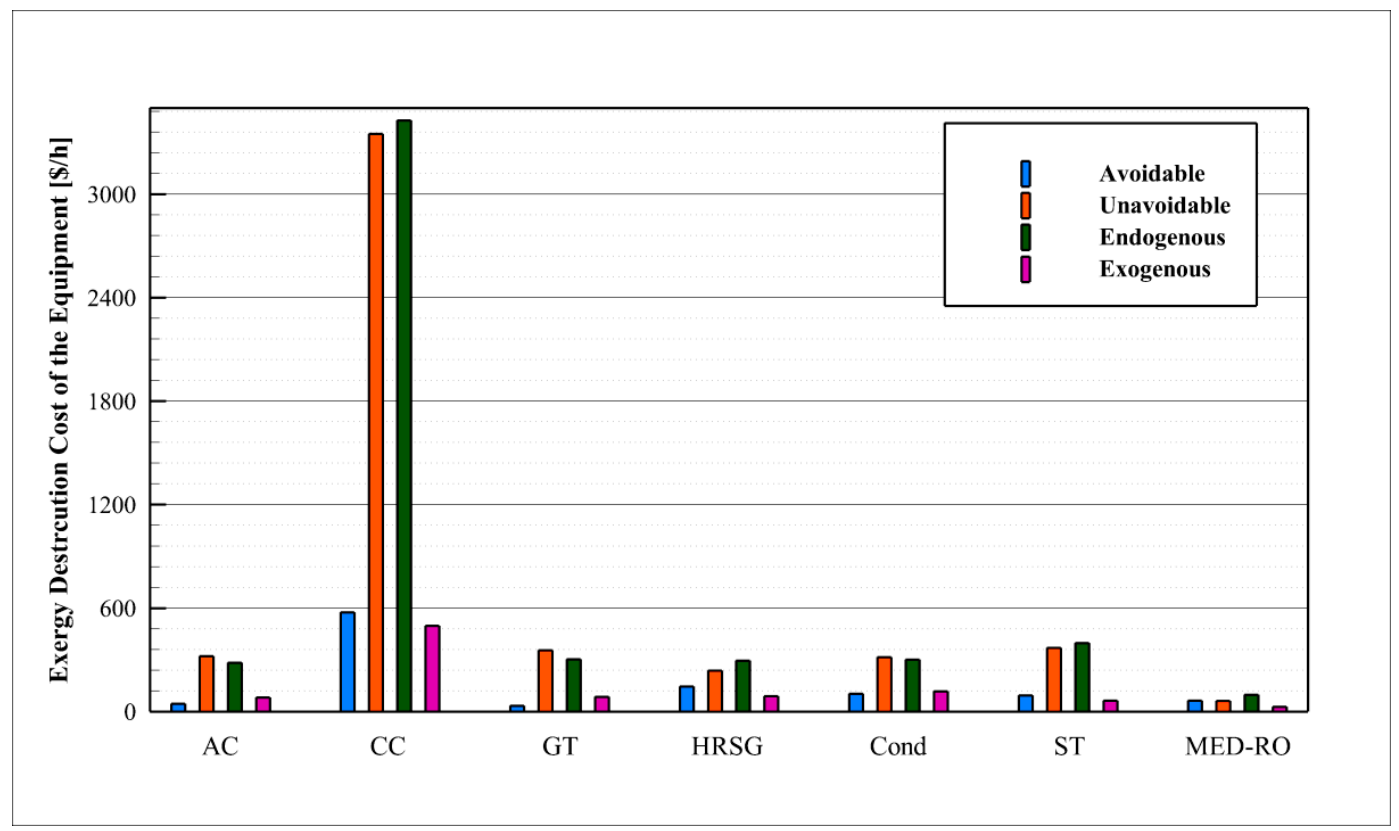

(b)

Figure 7. Distributions of avoidable/unavoidable and endogenous/exogenous exergy destruction cost for different system components in (a) relative values and (b) quantitative values. AC, air compressor; CC, combustion chamber; GT, gas turbine; HRSG, heat recovery steam generator; Cond, condenser; ST, steam turbine; MED-RO, multi-effect distillation and reverse osmosis system.

Figure 8 shows the distributions for environmental impacts of avoidable/unavoidable and endogenous/exogenous exergy destruction for different system components expressed in relative and quantitative values. According to Figure 8a, the highest proportions of environmental impacts of avoidable exergy destruction are related to the MED-RO desalination section $(51.37 \%)$, followed by the HRSG unit $(36.58 \%)$, condenser $(32.65 \%)$, and CC $(31.26 \%)$. Hence, in order to reduce the environmental effects of exergy destruction of different parts of the system, the aforementioned components present higher potential for improvements. In addition, the highest environmental impacts of endogenous exergy destruction belong to the CC $(86.35 \%)$, ST $(84.69 \%)$, and GT $(79.43 \%)$. Therefore, the CC, ST, 
and GT units are the most appropriate choices to reduce the relative environmental effects of exergy destruction among the system components.

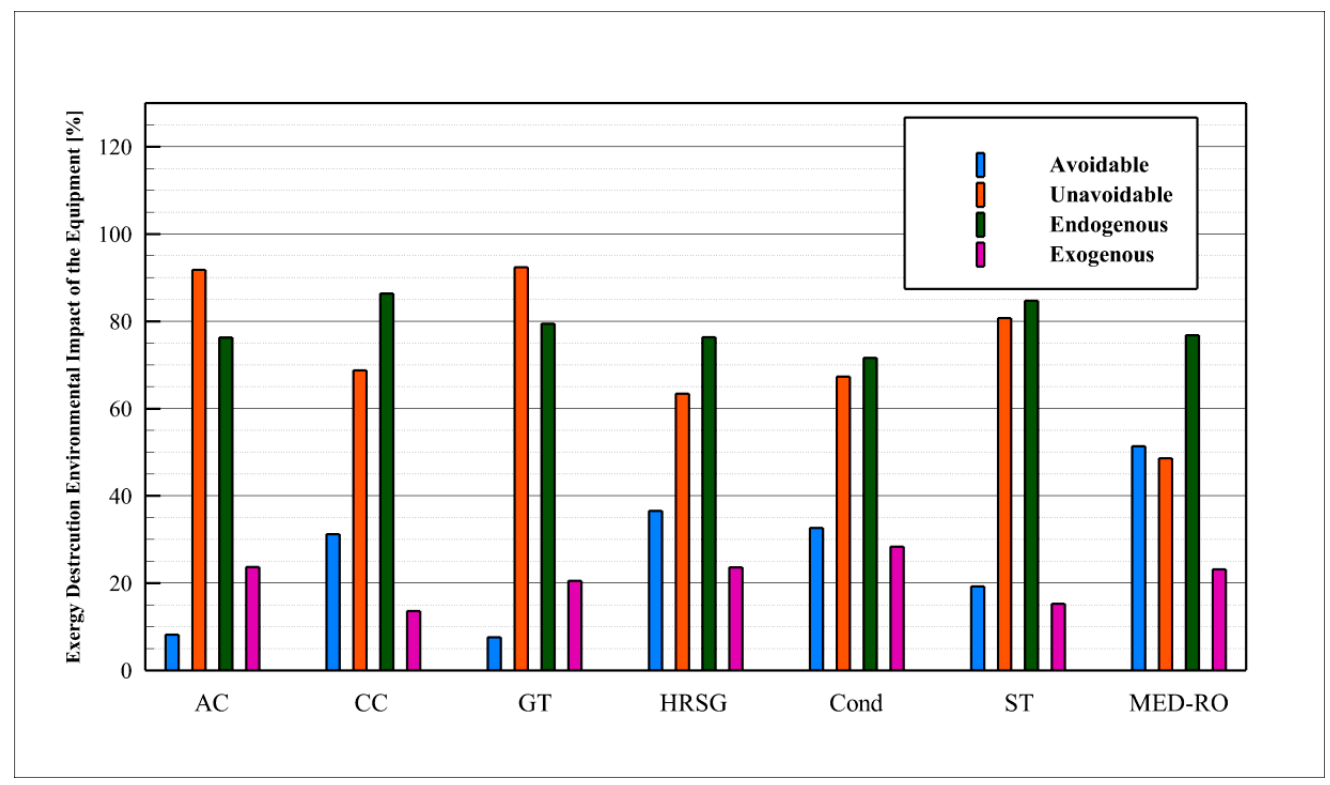

(a)

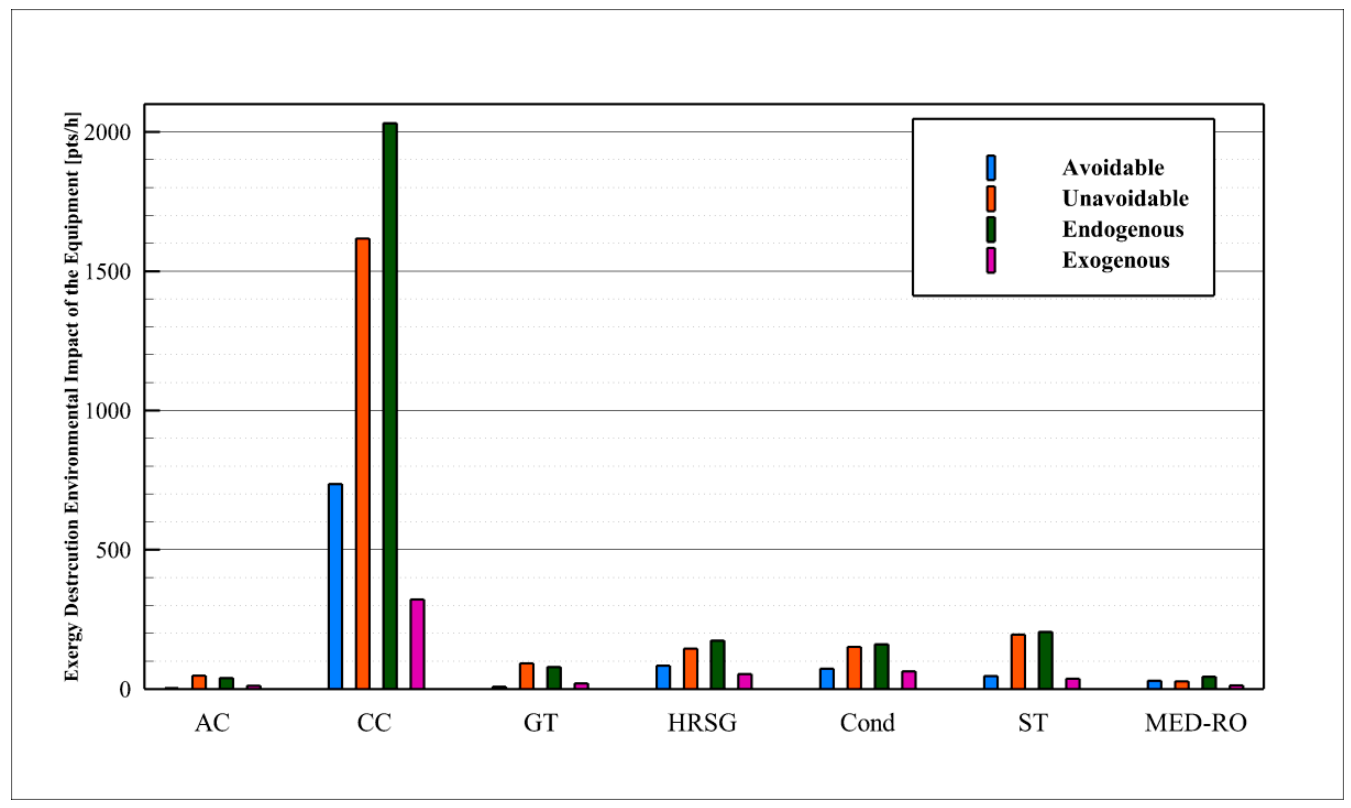

(b)

Figure 8. Distributions of avoidable/unavoidable and endogenous/exogenous environmental impacts of exergy destruction for different system components in (a) relative values and (b) quantitative values. AC, air compressor; CC, combustion chamber; GT, gas turbine; HRSG, heat recovery steam generator; Cond, condenser; ST, steam turbine; MED-RO, multi-effect distillation and reverse osmosis system.

Figure 8 also reveals that the maximum avoidable relative environmental impacts of exergy destruction can significantly differ from the maximum avoidable quantitative value in terms of equipment (i.e., the MED-RO desalination units present the maximum avoidable relative value for environmental impacts of exergy destruction, while the CC unit shows the maximum avoidable quantitative one). Similarly, the equipment with the highest relative value for unavoidable environmental impacts of exergy destruction will not necessarily have the highest quantitative value for the unavoidable environmental impacts 
of exergy destruction. Figure $8 \mathrm{~b}$ shows that the highest environmental impacts of avoidable exergy degradation is related to the CC (735.47 pts/h), followed by the HRSG unit (83.55 pts/h), condenser (73.24 pts/h), ST (46.59 pts/h), and MED-RO desalination units (29.58 pts/h). Additionally, the CC (2031.61 pts/h), ST (205.17 pts/h), HRSG (174.38 pts/h), and condenser $(160.73 \mathrm{pts} / \mathrm{h})$ present the highest environmental effects of endogenous exergy destruction. Therefore, performance improvements in the CC, ST, HRSG, and condenser units present the greatest potential for reducing the environmental effects of exergy destruction of the whole system.

\section{Conclusions}

Considering the need of different communities for electricity and freshwater, it is important to analyze and optimize the conditions for converting power plants into a cogeneration system. In this light, comprehensive thermodynamic, economic, and environmental analyses are performed to evaluate the potential conversion of a combined power plant into a simultaneous water and power production system. To do so, a thermodynamic modelling approach is proposed for the integrated combined cycle power plant with a multi-effect and reverse osmosis desalination system. In addition, conventional and advanced exergy, exergoeconomic, and exergoenvironmental analyses are carried out to appraise the main process performance parameters, as well as to identify potential technical, economic, and environmental improvements for the integrated system. A case study is presented based on the Neka power plant located at the north of Iran along the Caspian Sea.

In the exergy modelling of the existing Neka power plant and proposed integrated cycle, the results exhibit an exergy efficiency of $45.7 \%$ for the existing combined cycle, and $42.7 \%$ for the proposed cogeneration cycle. The highest cost of exergy destruction of the combustion chamber is 1.09 US\$ per second. Hence, these results indicate that the exergy efficiency of the power plant has decreased by about 3\% after the integration with the desalination units. Results of exergy destruction of the integrated system show that the combustion chamber, air compressor, and gas turbine units have the highest share of exergy destruction. Therefore, these equipment units present the highest improvement potential to diminish the exergy destruction of the whole system. As for the exergy efficiency of the proposed integrated system, gas turbines and air compressors present the highest values of $95 \%$ and $92 \%$, respectively, while reverse osmosis (19\%), multi-effect desalination plants $(31 \%)$, and condensers (34\%) have the lowest exergy efficiencies. In the economic evaluation of the proposed integrated system, results reveal that it is possible to reduce the investment and operating costs of the system by increasing the share of exergy destruction of the reverse osmosis desalination. This is due to the high exergoeconomic factor related to the reverse osmosis unit. Furthermore, the results of the economic assessment indicate that the production cost of electricity for the proposed integrated system is about 0.036 US\$ per kilowatt-hour, whereas the production costs of freshwater by the multi-effect desalination and reverse osmosis are $2.5 \mathrm{US} \$ / \mathrm{m}^{3}$ and $1.75 \mathrm{US} \$ / \mathrm{m}^{3}$, respectively.

In the environmental analysis of the proposed integrated cycle, the results show that the multi-effect desalination (with 90 points per hour), and the heat recovery steam generator (5.04 points per hour) have the most significant environmental effects on the proposed integrated cycle. The highest amount of environmental impacts due to the exergy destruction rate of the equipment belongs to the combustion chamber unit (2340 points per hour), while the lowest amount is presented by the air compressor ( 0.05 points per hour). This is owing to the exergy destruction of the corresponding equipment. The lowest values of the exergoenvironmental factor are related to the combustion chamber and condenser, and the highest ones are associated with the gas turbine (96\%) and air compressor (84\%). Finally, the results of the advanced exergy, exergoeconomic, and exergoenvironmental analysis reveal that the desalination units present the maximum avoidable relative values for the exergy destruction, exergy destruction cost, and environmental impacts of exergy destruction. The combustion chamber shows the maximum avoidable quantitative values for the same parameters. Moreover, the advanced analyses show that performance 
improvements in different equipment units can significantly reduce the exergy destruction, cost of exergy destruction, as well as the environmental effects of exergy destruction of the whole system.

The advanced exergy-based analyses performed in this study allows to identify the potential for technical, economic, and environmental improvements of different units in the integrated system. The system components identified by the previous analysis could be considered as the most appropriate options to enhance overall plant efficiency. Decreasing exergy destruction in these units allows improving their performance, which will lead to enhancing the efficiency of the whole plant, as well as diminishing their adverse effects on system's costs and environmental impacts. As these specific units have the highest impact on the system, the effect of their improvement will be significant. For improving the performance and thereby reducing the exergy destruction of the selected units, specific actions for each considered component should be conducted. Discussing the practical ways to prevent the irreversibility in different units is an attractive suggestion for future studies on the integrated system.

Author Contributions: Conceptualization, M.H.K.M.; methodology, R.S.G.; investigation, R.S.G.; software, R.S.G. and M.H.K.M.; data curation, R.S.G. and H.V.M.; formal analysis and results discussion, H.V.M., R.S.G. and V.C.O.; writing—original draft preparation, H.V.M.; writing—review and editing, V.C.O. and M.H.K.M.; validation, H.V.M. and M.H.K.M.; resources, M.H.K.M. and V.C.O.; visualization, H.V.M. All authors have read and agreed to the published version of the manuscript.

Funding: This research received no external funding.

Data Availability Statement: The data presented in this study are available on request to the corresponding author.

Conflicts of Interest: The authors declare no conflict of interest.

\section{Appendix A}

Table A1. Modelling equations for the multi-effect distillation (MED) system [19].

\begin{tabular}{|c|c|}
\hline Component & Modelling Equations \\
\hline MED & 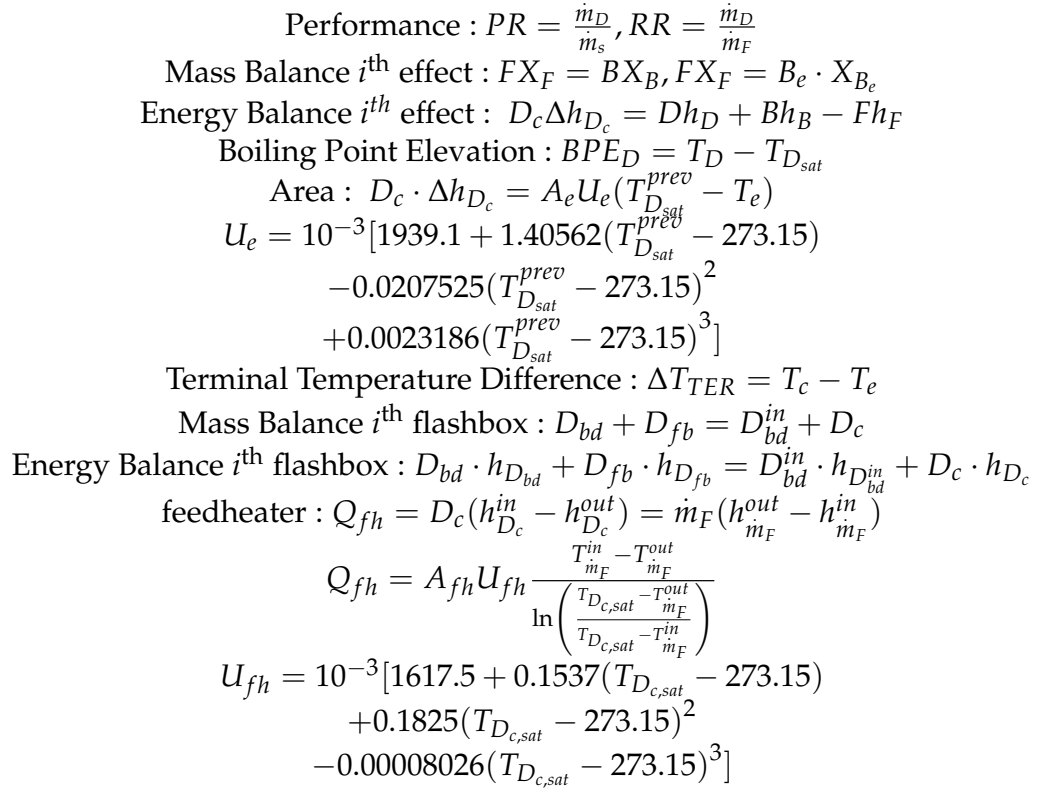 \\
\hline
\end{tabular}


Table A1. Cont.

\begin{tabular}{cc}
\hline Component & Modelling Equations \\
\hline$Q_{c o n d}=D_{c}\left(h_{D_{c}}^{\text {in }}-h_{D_{c}}^{\text {out }}\right)=\dot{m}_{c o n d}\left(h_{s w}^{\text {out }}-h_{s w}^{\text {in }}\right)$ \\
$Q_{c o n d}=A_{c} U_{c} \frac{T_{s w}^{\text {in }}-T_{s w w}^{\text {out }}}{\ln \left(\frac{T_{D}-T_{s w}^{\text {in }}}{T_{D}-T_{s w w}^{\text {out }}}\right)}$ \\
$U_{c}=10^{-3}\left[1617.5+0.1537\left(T_{D}-273.15\right)\right.$ \\
$+0.1825\left(T_{D}-273.15\right)^{2}$ \\
$\left.-0.00008026\left(T_{D}-273.15\right)^{3}\right]$ \\
$\dot{m}_{D}=\sum_{i=1}^{n} D(i)$ \\
$\dot{m}_{S}=D_{c}(1)$ \\
$\dot{m}_{F}=F(1)$ \\
$\dot{m}_{B}=B(n)$ \\
Sondenser \\
Specific Area $: S A=\frac{\sum A_{e}+\sum A_{f h}+A_{c}}{\dot{m}_{D}}$ \\
\hline
\end{tabular}

Table A2. Modelling equations for the RO desalination unit [3].

\begin{tabular}{|c|}
\hline Modelling Equations \\
\hline 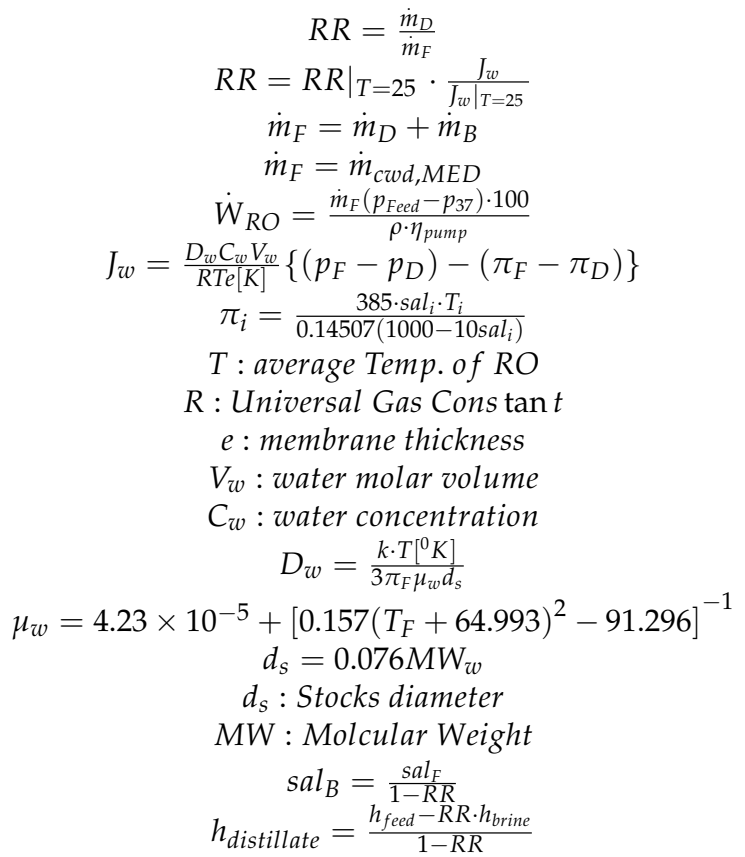 \\
\hline
\end{tabular}

Table A3. Capital investment for different system components.

\begin{tabular}{|c|c|c|}
\hline $\begin{array}{c}\text { System } \\
\text { Component }\end{array}$ & Cost Equation (US\$) & Reference \\
\hline $\mathrm{AC}$ & $44.71 \cdot m_{a} \cdot r_{p, A C} \cdot \ln \left(r_{p, A C}\right) \frac{1}{0.95-\eta_{A C}}$ & [21] \\
\hline $\mathrm{CC}$ & $\frac{28.98 m_{a}}{0.995-\left(\frac{p_{\text {out }}}{n_{\text {t }}}\right)}\left(1+e^{\left(0.015\left(T_{\text {out }}-1540\right)\right)}\right)$ & [21] \\
\hline GT & $479.34 \frac{m_{f g}}{0.93-\eta_{G T}} \ln \left(r_{p, G T}\right)\left(1+e^{\left(0.036 T_{\text {in }}-54.4\right)}\right)$ & {$[33]$} \\
\hline HRSG & $6570\left[\left(\frac{Q_{E C}}{\Delta T_{E C}}\right)^{0.8}+\left(\frac{Q_{E V}}{\Delta T_{E V}}\right)^{0.8}+\left(\frac{Q_{S H}}{\Delta T_{S H}}\right)^{0.8}\right]+21276 \cdot m_{w}$ & [33] \\
\hline Deaerator & $6570\left(\frac{Q_{D E A}}{\Delta T_{D E A}}\right)^{0.8}$ & [25] \\
\hline
\end{tabular}


Table A3. Cont.

\begin{tabular}{|c|c|c|}
\hline $\begin{array}{l}\text { System } \\
\text { Component }\end{array}$ & Cost Equation (US\$) & Reference \\
\hline Pump & $3540 \cdot W_{\text {Pump }}^{0.71}$ & {$[34]$} \\
\hline MED & $\begin{array}{c}\sum P E C_{\text {effects }}+\sum P E C_{\text {feed-heaters }}+\sum P E C_{\text {flash-boxes }}+P E C_{\text {condenser }} \\
P E C_{H X}=12,000\left(\frac{\text { Area }}{100}\right)^{0.6}\end{array}$ & [25] \\
\hline \multirow{3}{*}{$\mathrm{RO}$} & $\begin{array}{c}P E C_{\text {membrane }}+P E C_{\text {pretreat }}+P E C_{R O-\text { pump }}+P E C_{R O-\text { valve }} \\
P E C_{\text {membrane }}=N O \cdot \text { membranes } \\
P E C_{\text {one-membrane }}\end{array}$ & \\
\hline & $\begin{array}{c}P E C_{\text {one-membrane }}=7846 \\
P E C_{\text {pretreat }}=996 \cdot \xi_{1}\left(\frac{\dot{m}_{R O-f e e d}}{\rho} \cdot 24 \cdot 3600\right)^{0.8}\end{array}$ & {$[35,36]$} \\
\hline & $\begin{array}{l}\xi_{1}=1.399: \text { inflation factor } \\
P E C_{R O-\text { pump }}=393,000 \xi_{1}+701.19 \cdot 14.5 \cdot P_{R O-\text { feed }} \\
P E C_{R O-\text { valve }}=8.07 \cdot 0.989 \dot{m}\left(\frac{T_{i}}{P_{i}}\right)^{0.05} P_{e}{ }^{-0.75}\end{array}$ & \\
\hline ST & $\frac{\eta_{S T}}{0.85} \times 10^{\left(2.6259+1.4398 * \log 10\left(W_{S T}\right)-0.1776\left(\log 10\left(W_{S} T\right)\right)^{2}\right)}$ & [34] \\
\hline
\end{tabular}

$\overline{\mathrm{AC}}$, air compressor; $\mathrm{CC}$, combustion chamber; GT, gas turbine; HRSG, heat recovery steam generator; MED, multi-effect distillation; RO, reverse osmosis; ST, steam turbine.

Table A4. Verification of thermodynamic simulation results of the different process streams.

\begin{tabular}{|c|c|c|c|c|c|c|c|c|c|}
\hline & \multicolumn{3}{|c|}{$\dot{m}(\mathrm{~kg} / \mathrm{s})$} & \multicolumn{3}{|c|}{$T\left({ }^{\circ} \mathrm{C}\right)$} & \multicolumn{3}{|c|}{$P$ (bar) } \\
\hline & MATLAB & Thermoflex & Error (\%) & MATLAB & Thermoflex & Error (\%) & MATLAB & Thermoflex & Error (\%) \\
\hline 1 & 495.60 & 491.10 & 0.92 & 20.00 & 20.00 & 0.00 & 1.010 & 1.010 & 0.00 \\
\hline 2 & 495.60 & 491.10 & 0.92 & 337.25 & 344.40 & 2.08 & 10.800 & 10.800 & 0.00 \\
\hline 3 & 504.30 & 498.90 & 1.08 & 971.00 & 970.90 & 0.01 & 10.001 & 10.300 & 2.90 \\
\hline 4 & 504.30 & 498.90 & 1.08 & 502.12 & 528.40 & 4.97 & 1.010 & 1.030 & 1.94 \\
\hline 5 & 504.30 & 498.90 & 1.08 & 502.12 & 528.40 & 4.97 & 1.010 & 1.030 & 1.94 \\
\hline 8 & 504.30 & 498.90 & 1.08 & 436.26 & 441.30 & 1.14 & 1.010 & 1.030 & 1.94 \\
\hline 9 & 504.30 & 498.90 & 1.08 & 311.01 & 318.70 & 2.41 & 1.010 & 1.030 & 1.94 \\
\hline 10 & 504.30 & 498.90 & 1.08 & 252.89 & 257.90 & 1.94 & 1.010 & 1.020 & 0.98 \\
\hline 11 & 504.30 & 498.90 & 1.08 & 250.93 & 255.60 & 1.83 & 1.010 & 1.020 & 0.98 \\
\hline 12 & 504.30 & 498.90 & 1.08 & 221.69 & 231.10 & 4.07 & 1.010 & 1.020 & 0.98 \\
\hline 13 & 504.30 & 498.90 & 1.08 & 200.39 & 206.40 & 2.91 & 1.010 & 1.010 & 0.00 \\
\hline 14 & 504.30 & 498.90 & 1.08 & 197.02 & 202.60 & 2.76 & 1.010 & 1.010 & 0.00 \\
\hline 15 & 504.30 & 498.90 & 1.08 & 168.50 & 168.20 & 0.18 & 1.010 & 1.010 & 0.00 \\
\hline 16 & 63.03 & 60.72 & 3.80 & 61.43 & 61.45 & 0.04 & 0.213 & 0.213 & 0.00 \\
\hline 17 & 63.03 & 60.72 & 3.80 & 63.21 & 61.45 & 2.86 & 0.221 & 0.213 & 3.76 \\
\hline 18 & 63.03 & 60.72 & 3.80 & 63.21 & 61.45 & 2.86 & 0.221 & 0.213 & 3.76 \\
\hline 19 & 66.70 & 63.93 & 4.33 & 63.23 & 61.54 & 2.75 & 4.900 & 4.938 & 0.77 \\
\hline 20 & 66.70 & 63.93 & 4.33 & 63.23 & 60.78 & 4.03 & 4.900 & 4.938 & 0.77 \\
\hline 21 & 66.70 & 63.93 & 4.33 & 126.00 & 126.70 & 0.55 & 4.900 & 4.938 & 0.77 \\
\hline 22 & 8.98 & 9.18 & 2.17 & 126.06 & 128.90 & 2.20 & 10.000 & 10.450 & 4.31 \\
\hline 23 & 55.74 & 54.75 & 1.81 & 126.87 & 128.90 & 1.58 & 96.000 & 98.900 & 2.93 \\
\hline 24 & 8.98 & 9.18 & 2.17 & 179.89 & 181.80 & 1.05 & 10.000 & 10.450 & 4.31 \\
\hline 25 & 8.98 & 9.18 & 2.17 & 179.89 & 181.80 & 1.05 & 10.000 & 10.340 & 3.29 \\
\hline 26 & 8.98 & 9.18 & 2.17 & 236.00 & 236.50 & 0.21 & 10.000 & 10.340 & 3.29 \\
\hline 27 & 55.74 & 54.75 & 1.81 & 180.00 & 185.00 & 2.70 & 96.000 & 97.900 & 1.94 \\
\hline 28 & 55.74 & 54.75 & 1.81 & 308.01 & 308.70 & 0.22 & 96.000 & 96.900 & 0.93 \\
\hline 29 & 55.74 & 54.75 & 1.81 & 308.01 & 308.70 & 0.22 & 96.000 & 96.900 & 0.93 \\
\hline 32 & 55.74 & 54.75 & 1.81 & 523.00 & 522.00 & 0.19 & 96.000 & 96.000 & 0.00 \\
\hline 33 & 3.28 & 3.22 & 1.86 & 236.00 & 236.50 & 0.21 & 10.000 & 10.340 & 3.29 \\
\hline 34 & 3.28 & 3.22 & 1.86 & 70.00 & 70.11 & 0.16 & 4.900 & 4.930 & 0.61 \\
\hline 35 & 79.14 & 82.86 & 4.49 & 20.00 & 20.00 & 0.00 & 1.010 & 1.010 & 0.00 \\
\hline 36 & 13.48 & 13.60 & 0.88 & 44.00 & 44.49 & 1.10 & 1.010 & 1.014 & 0.39 \\
\hline 37 & 46.66 & 48.75 & 4.29 & 48.00 & 47.60 & 0.84 & 1.010 & 1.014 & 0.39 \\
\hline 38 & 20.00 & 20.00 & 0.00 & 47.49 & 46.54 & 2.04 & 4.500 & 4.500 & 0.00 \\
\hline 39 & 6.84 & 6.90 & 0.87 & 44.00 & 46.13 & 4.62 & 1.010 & 1.010 & 0.00 \\
\hline 40 & 6.54 & 6.60 & 0.91 & 46.75 & 47.69 & 1.97 & 1.010 & 1.010 & 0.00 \\
\hline
\end{tabular}


Table A5. Verification of thermodynamic simulation results of the different system components.

\begin{tabular}{cccc}
\hline System Components & MATLAB (MW) & Thermoflex (MW) & Error (\%) \\
\hline$W_{G T \text { Pack }}$ & 132.15 & 132.02 & 0.10 \\
$W_{A C}$ & 158.02 & 159.63 & 1.01 \\
$W_{G T}$ & 290.16 & 291.65 & 0.51 \\
$Q_{H P S H}$ & 40.76 & 42.05 & 3.07 \\
$Q_{L P S H}$ & 18.1 & 18.23 & 0.71 \\
$Q_{H P E V}$ & 77.51 & 73.82 & 5.00 \\
$Q_{L P E V}$ & 18.11 & 18.55 & 2.37 \\
$Q_{H P E C 2}$ & 35.97 & 34.39 & 4.59 \\
$Q_{H P E C 1}$ & 13.18 & 13.31 & 0.98 \\
$Q_{L P E C}$ & 2.09 & 2.05 & 1.95 \\
$Q_{P R E}$ & 17.65 & 17.86 & 1.18 \\
$W_{S T}$ & 64.78 & 62.76 & 3.22 \\
$Q_{\text {cond }}$ & 140.27 & 138.58 & 1.22 \\
$P R_{M E D}$ & 5.41 & 5.32 & 1.69 \\
$R_{\text {RO }}$ & 0.5242 & 0.512 & 2.38 \\
\hline
\end{tabular}

Table A6. Conventional exergy, economic and environmental results for the different process streams.

\begin{tabular}{|c|c|c|c|c|c|c|c|c|}
\hline $\begin{array}{l}\text { Process } \\
\text { Streams }\end{array}$ & $\dot{m}(\mathrm{~kg} / \mathrm{s})$ & $T\left({ }^{\circ} \mathrm{C}\right)$ & $P$ (bar) & $\dot{E x}(\mathrm{MW})$ & $\begin{array}{c}C \\
\mathrm{US} \$ / \mathrm{GJ}\end{array}$ & $\begin{array}{c}\dot{C} \\
\mathrm{US} \$ / \mathrm{min}\end{array}$ & $\begin{array}{c}b \\
\text { (pts/GJ) }\end{array}$ & $\begin{array}{c}B \\
\text { (pts/h) }\end{array}$ \\
\hline 1 & 495.60 & 20.00 & 1.010 & 0.00 & 0.00 & 0.00 & 0.00 & 0.00 \\
\hline 2 & 495.60 & 337.25 & 10.800 & 146.94 & 10.13 & 89.29 & 5.78 & 3055.32 \\
\hline 3 & 504.30 & 971.00 & 10.001 & 424.59 & 8.63 & 219.95 & 5.15 & 7865.85 \\
\hline 4 & 504.30 & 502.12 & 1.010 & 121.93 & 8.63 & 63.16 & 5.15 & 2258.82 \\
\hline 5 & 504.30 & 502.12 & 1.010 & 121.93 & 8.63 & 63.16 & 5.15 & 2258.82 \\
\hline 8 & 504.30 & 436.26 & 1.010 & 97.28 & 8.63 & 50.39 & 5.15 & 1802.13 \\
\hline 9 & 504.30 & 311.01 & 1.010 & 55.01 & 8.63 & 28.50 & 5.15 & 1019.06 \\
\hline 10 & 504.30 & 252.89 & 1.010 & 38.05 & 8.63 & 19.71 & 5.15 & 704.94 \\
\hline 11 & 504.30 & 250.93 & 1.010 & 37.52 & 8.63 & 19.43 & 5.15 & 695.02 \\
\hline 12 & 504.30 & 221.69 & 1.010 & 29.83 & 8.63 & 15.45 & 5.15 & 552.70 \\
\hline 13 & 504.30 & 200.39 & 1.010 & 24.64 & 8.63 & 12.76 & 5.15 & 456.42 \\
\hline 14 & 504.30 & 197.02 & 1.010 & 23.85 & 8.63 & 12.35 & 5.15 & 441.75 \\
\hline 15 & 504.30 & 168.50 & 1.010 & 17.55 & 8.63 & 9.09 & 5.15 & 325.10 \\
\hline 16 & 63.03 & 61.43 & 0.213 & 16.54 & 10.83 & 10.75 & 5.80 & 345.52 \\
\hline 17 & 63.03 & 63.21 & 0.221 & 0.13 & 10.83 & 0.08 & 5.80 & 2.71 \\
\hline 18 & 63.03 & 63.21 & 0.221 & 0.13 & 10.83 & 0.08 & 5.80 & 2.71 \\
\hline 19 & 66.70 & 63.23 & 4.900 & 0.16 & 13.10 & 0.13 & 6.05 & 3.47 \\
\hline 20 & 66.70 & 63.23 & 4.900 & 0.17 & 13.10 & 0.13 & 6.05 & 3.67 \\
\hline 21 & 66.70 & 126.00 & 4.900 & 3.72 & 18.17 & 4.05 & 8.99 & 120.35 \\
\hline 22 & 8.98 & 126.06 & 10.000 & 0.51 & 18.28 & 0.55 & 8.97 & 16.32 \\
\hline 23 & 55.74 & 126.87 & 96.000 & 3.78 & 17.94 & 4.07 & 8.65 & 117.76 \\
\hline 24 & 8.98 & 179.89 & 10.000 & 1.16 & 19.30 & 1.34 & 7.44 & 30.99 \\
\hline 25 & 8.98 & 179.89 & 10.000 & 7.54 & 13.06 & 5.91 & 6.38 & 173.38 \\
\hline 26 & 8.98 & 236.00 & 10.000 & 8.02 & 14.30 & 6.88 & 6.41 & 184.85 \\
\hline 27 & 55.74 & 180.00 & 96.000 & 7.89 & 15.69 & 7.43 & 7.53 & 214.07 \\
\hline 28 & 55.74 & 308.01 & 96.000 & 23.49 & 12.55 & 17.68 & 6.25 & 528.28 \\
\hline 29 & 55.74 & 308.01 & 96.000 & 61.90 & 11.14 & 41.37 & 5.89 & 1311.53 \\
\hline 32 & 55.74 & 523.00 & 96.000 & 84.77 & 10.83 & 55.10 & 5.80 & 1771.38 \\
\hline 33 & 3.28 & 236.00 & 10.000 & 3.34 & 14.30 & 2.87 & 6.41 & 77.10 \\
\hline 34 & 3.28 & 70.00 & 4.900 & 0.07 & 14.30 & 0.06 & 6.41 & 1.71 \\
\hline 35 & 79.14 & 20.00 & 1.010 & 0.20 & 0.00 & 0.00 & 0.00 & 0.00 \\
\hline 36 & 13.48 & 44.00 & 1.010 & 0.08 & 0.00 & 0.00 & 0.00 & 0.00 \\
\hline 37 & 46.66 & 48.00 & 1.010 & 0.81 & 0.00 & 0.00 & 0.00 & 0.00 \\
\hline 38 & 20.00 & 47.49 & 4.500 & 0.16 & 316.89 & 3.01 & 295.28 & 168.33 \\
\hline 39 & 6.84 & 44.00 & 1.010 & 0.04 & 288.32 & 0.72 & 36.42 & 5.48 \\
\hline 40 & 6.54 & 46.75 & 1.010 & 0.22 & 0.00 & 0.00 & 0.00 & 0.00 \\
\hline
\end{tabular}




\section{References}

1. Najafi, B.; Shirazi, A.; Aminyavari, M.; Rinaldi, F.; Taylor, R. A Exergetic, economic and environmental analyses and multiobjective optimization of an SOFC-gas turbine hybrid cycle coupled with an MSF desalination system. Desalination 2014, 334, 46-59. [CrossRef]

2. Modabber, H.V.; Manesh, M.H.K. Optimal Exergetic, Exergoeconomic and Exergoenvironmental Design of Polygeneration System based on Gas Turbine-Absorption Chiller-Solar Parabolic Trough Collector Units Integrated with Multi-Effect DesalinationThermal Vapor Compressor- Reverse Osmosis Desalination Systems. Renew. Energy 2020, 165, 533-552.

3. Al-Zahrani, A.; Orfi, J.; Al-Suhaibani, Z.; Salim, B.; Al-Ansary, H. Thermodynamic Analysis of a Reverse Osmosis Desalination Unit with Energy Recovery System. Procedia Eng. 2012, 33, 404-414. [CrossRef]

4. Sadri, S.; Ameri, M.; Khoshkhoo, R.H. Multi-objective optimization of MED-TVC-RO hybrid desalination system based on the irreversibility concept. Desalination 2017, 402, 97-108. [CrossRef]

5. Blanco-Marigorta, A.M.; Masi, M.; Manfrida, G. Exergo-environmental analysis of a reverse osmosis desalination plant in Gran Canaria. Energy 2014, 76, 223-232. [CrossRef]

6. Calise, F.; d'Accadia, M.D.; Piacentino, A. Exergetic and exergoeconomic analysis of a renewable polygeneration system and viability study for small isolated communities. Energy 2015, 92, 290-307. [CrossRef]

7. Mokhtari, H.; Sepahvand, M. Thermoeconomic and exergy analysis in using hybrid systems $(G T+M E D+R O)$ for desalination of brackish water in Persian Gulf. Desalination 2016, 399, 1-15. [CrossRef]

8. Almutairi, A.; Pilidis, P.; Al-Mutawa, N.; Al-Weshahi, M. Energetic and exergetic analysis of cogeneration power combined cycle and ME-TVC-MED water desalination plant: Part-1 operation and performance. Appl. Therm. Eng. 2016, 103, 77-91. [CrossRef]

9. Shahzad, M.W.; Ng, K.C.; Thu, K. An improved cost apportionment for desalination combined with power plant: An exergetic analyses. In Applied Mechanics and Materials; Trans Tech Publications Ltd.: Stafa-Zurich, Switzerland, 2016.

10. Eveloy, V.; Rodgers, P.; Qiu, L. Integration of an atmospheric solid oxide fuel cell-gas turbine system with reverse osmosis for distributed seawater desalination in a process facility. Energy Convers. Manag. 2016, 126, 944-959. [CrossRef]

11. Ng, K.C.; Shahzad, M.W.; Son, H.S.; Hamed, O. A An exergy approach to efficiency evaluation of desalination. Appl. Phys. Lett. 2017, 110, 184101. [CrossRef]

12. Arani, A.M.A.; Zamani, V.; Behbahaninia, A. Economic analysis of a combined power and desalination plant considering availability changes due to degradation. Desalination 2017, 414, 1-9. [CrossRef]

13. Salimi, M.; Amidpour, M. Investigating the integration of desalination units into cogeneration systems utilizing R-curve tool. Desalination 2017, 419, 49-59. [CrossRef]

14. Ameri, M.; Ahmadi, P.; Khanmohammadi, S. Exergy analysis of a 420 MW combined cycle power plant. Int. J. Energy Res. 2008, 32, 175-183.

15. Vazini Modabber, H.; Manesh, M.H.K. Exergetic Exergoeconomic and Exergoenvironmental Multi-Objective Genetic Algorithm Optimization of Qeshm Power and Water Cogeneration Plant. Gas Process. 2019, 7, 1-28.

16. Moghimi, M.; Emadi, M.; Akbarpoor, A.M.; Mollaei, M. Energy and exergy investigation of a combined cooling, heating, power generation, and seawater desalination system. Appl. Therm. Eng. 2018, 140, 814-827. [CrossRef]

17. Petrakopoulou, F.; Tsatsaronis, G.; Morosuk, T. Advanced Exergoeconomic Analysis of a Power Plant with CO2 Capture. Energy Procedia 2015, 75, 2253-2260. [CrossRef]

18. Bejan, A.; Tsatsaronis, G.; Moran, M.J. Thermal Design and Optimization; Wiley: New York, NY, USA, 1996.

19. Mistry, K.H.; Antar, M.A.; Lienhard, J.H. An improved model for multiple effect distillation. Desalination Water Treat. 2013, 51, 807-821. [CrossRef]

20. Wagner, W.; Kretzschmar, H.J. International Steam Tables_Properties of Water and Steam based on the Industrial Formulation IAPWSIF97: Tables, Algorithms, Diagrams, and CD-ROM Electronic Steam Tables-All of the Equations of IAPWS-IF97 Including a Complete Set of Supplementary Backward Equations for Fast Calculations of Heat Cycles, Boilers, and Steam Turbines; Springer: Berlin/Heidelberg, Germany, 2007.

21. Dincer, I.; Rosen, M.A.; Ahmadi, P. Optimization of Energy Systems; Wiley: New York, NY, USA, 2017.

22. Valero, A.; Lozano, M.A.; Serra, L.; Tsatsaronis, G.; Pisa, J.; Frangopoulos, C.; von Spakovsky, M.R. CGAM problem: Definition and conventional solution. Energy 1994, 19, 279-286. [CrossRef]

23. Dincer, I.; Rosen, M.A. Chapter 3-Chemical Exergy, in Exergy, 2nd ed.; Dincer, I., Rosen, M.A., Eds.; Elsevier: Amsterdam, The Netherlands, 2013; pp. 31-49.

24. Sharqawy, M.H.; Zubair, S.M.; Lienhard, J.H. Second law analysis of reverse osmosis desalination plants: An alternative design using pressure retarded osmosis. Energy 2011, 36, 6617-6626. [CrossRef]

25. Cavalcanti, E.J.C. Exergoeconomic and exergoenvironmental analyses of an integrated solar combined cycle system. Renew. Sustain. Energy Rev. 2017, 67, 507-519. [CrossRef]

26. Goedkoop, M.; Effting, S.; Collignon, M. The Eco-indicator 99: A Damage Oriented Method for Life-cycle Impact Assessment : Manual for Designers; PRé, Product Ecology Consultants: Amersfoort, The Netherlands, 2000.

27. Raluy, G.; Serra, L.; Uche, J. Life cycle assessment of MSF, MED and RO desalination technologies. Energy 2006, 31, 2361-2372. [CrossRef]

28. Petrakopoulou, F.; Tsatsaronis, G.; Morosuk, T.; Carassai, A. Advanced exergoeconomic analysis applied to a complex energy conversion system. J. Eng. Gas Turbines Power 2012, 134, 031801. [CrossRef] 
29. Tsatsaronis, G.; Park, M.-H. On avoidable and unavoidable exergy destructions and investment costs in thermal systems. Energy Convers. Manag. 2002, 43, 1259-1270. [CrossRef]

30. Anvari, S.; Saray, R.K.; Bahlouli, K. Conventional and advanced exergetic and exergoeconomic analyses applied to a tri-generation cycle for heat, cold and power production. Energy 2015, 91, 925-939. [CrossRef]

31. Boyano, A.; Morosuk, T.; Blanco-Marigorta, A.M.; Tsatsaronis, G. Conventional and advanced exergoenvironmental analysis of a steam methane reforming reactor for hydrogen production. J. Clean. Prod. 2012, 20, 152-160. [CrossRef]

32. Zhou, W.; Song, L.; Guan, T.K. A numerical study on concentration polarization and system performance of spiral wound RO membrane modules. J. Membr. Sci. 2006, 271, 38-46. [CrossRef]

33. Ghaebi, H.; Saidi, M.H.; Ahmadi, P. Exergoeconomic optimization of a trigeneration system for heating, cooling and power production purpose based on TRR method and using evolutionary algorithm. Appl. Therm. Eng. 2012, 36, 113-125. [CrossRef]

34. Boyaghchi, F.A.; Heidarnejad, P. Thermoeconomic assessment and multi objective optimization of a solar micro CCHP based on Organic Rankine Cycle for domestic application. Energy Convers. Manag. 2015, 97, 224-234. [CrossRef]

35. Park, C.; Park, P.K.; Mane, P.P.; Hyung, H.; Gandhi, V.; Kim, S.H.; Kim, J.H. Stochastic cost estimation approach for full-scale reverse osmosis desalination plants. J. Membr. Sci. 2010, 364, 52-64. [CrossRef]

36. El-Sayed, Y.M. The Thermoeconomics of Energy Conversions; Elsevier Science: Amsterdam, The Netherlands, 2013. 